\title{
Effect of urban geometry on pedestrian-level wind velocity
}

\author{
Celen Ayse Arkon ${ }^{\mathrm{a} *}$ and Ünver Özkol ${ }^{\mathrm{b}}$ \\ ${ }^{a}$ Faculty of Architecture, Yasar University, Izmir, Turkey; ${ }^{b}$ Department of Mechanical Engineering, Izmir Institute of Technology, Izmir, \\ Turkey
}

(Received 14 January 2013; final version received 3 August 2013)

\begin{abstract}
The orientation of the streets and the height of continuous buildings cut off summer breezes and the prevailing wind in Izmir, Turkey. Compared with the northern parts of Turkey, the summer period in Izmir is relatively hot, humid and long. Due to the dense urban structure and the expansion of hard surface materials, the temperature in the city centre is higher than this centre's surroundings and this effect is called the urban heat island. Consequently, pedestrian comfort in the city drops dramatically especially in locations where the wind flow is obstructed by buildings. In addition, natural ventilation through the building façades is weakened due to the low average wind speed in the streets. For better outdoor and indoor comfort the citizens in Izmir should benefit from the prevailing wind and summer breezes locally named 'imbat' in the sea-land direction. Therefore, the existing situation is examined through the field study in order to understand the natural ventilation potential at the pedestrian level in the selected main streets in Izmir.
\end{abstract}

Keywords: UHI mitigation; urban geometry; urban canyon; wind speed; wind direction; field study

\section{Introduction}

Enhancing the wind environment is one of the mitigation methods of urban heat island (UHI) effect which is simply defined by many scientists as the temperature difference between rural and urban areas (Givoni 1998; Santamouris et al. 2001; Karatasou, Santamouris, and Geros 2006). On temperature maps obtained from satellite images these differences are concentrated in specific locations in urban areas under certain circumstances similar to 'islands'. Urban climatologists then realized that these areas mostly refer to locations where deep and long streets are situated (Oke 1988; Gallo et al. 1995; Pongrácz, Bartholy, and Dezső 2006; Pongrácz, Bartholy, and Dezső 2010; Sobrino et al. 2012). In the UHI literature, these streets have special characteristics such as aspect ratios and are called 'urban canyons', channelling the wind similar to natural canyons. The aspect ratios are formed by three-dimensional characteristics such as the average length and width of the streets, the average height of buildings, etc. Urban canyons have been investigated many times through field studies, simulation studies and wind tunnel studies (Oke 1988; Santamouris 2001; Ahmad, Khare, and Chaundry 2005; Karatasou, Santamouris, and Geros 2006; Gao et al. 2012; Moonen et al. 2012).

The aim of this study is to investigate the wind environment in Izmir as a solution to the UHI effect by using the factors of wind speed and direction through a field study.
Roof- and pedestrian-level wind velocities are analysed to understand the natural cooling potential.

Therefore, in order to find guidelines for better urban designs, the wind environment in the existing streets in Izmir central area has been tested. Three locations on the South of Izmir Bay were selected. These are Alsancak, Konak and Güzelyalı as shown in Figure 1. Potential urban canyons are selected as the busiest streets in the sites in terms of vehicular and pedestrian traffic and also according to their depth and longitude (represented by the aspect ratios). Therefore, two parallel deep canyons in Alsancak, two shallow canyons in Konak and one medium-depth canyon in Güzelyalı were selected. Streets in proximity to the seaside on the South of the bay were selected in order to find if the summer breeze 'imbat' and the prevailing wind penetrate into them. Wind speed at the pedestrian level was measured; the wind speed and direction data were also collected from the National Meteorology Office (NMO) located in Güzelyalı (Figure 1(b)). Plan and section diagrams were used to show the connection of the seaside with the existing and potential air paths in the aforementioned canyons, shown in Figure 1(b).

However, field studies on urban wind environment are very rare since they are expensive, difficult and risky. This is because it is difficult to understand governing forces that affect wind speed and direction. Despite this they are very valuable compared with the simulation studies since a wide

\footnotetext{
*Corresponding author. Email: celenarkon@gmail.com
} 

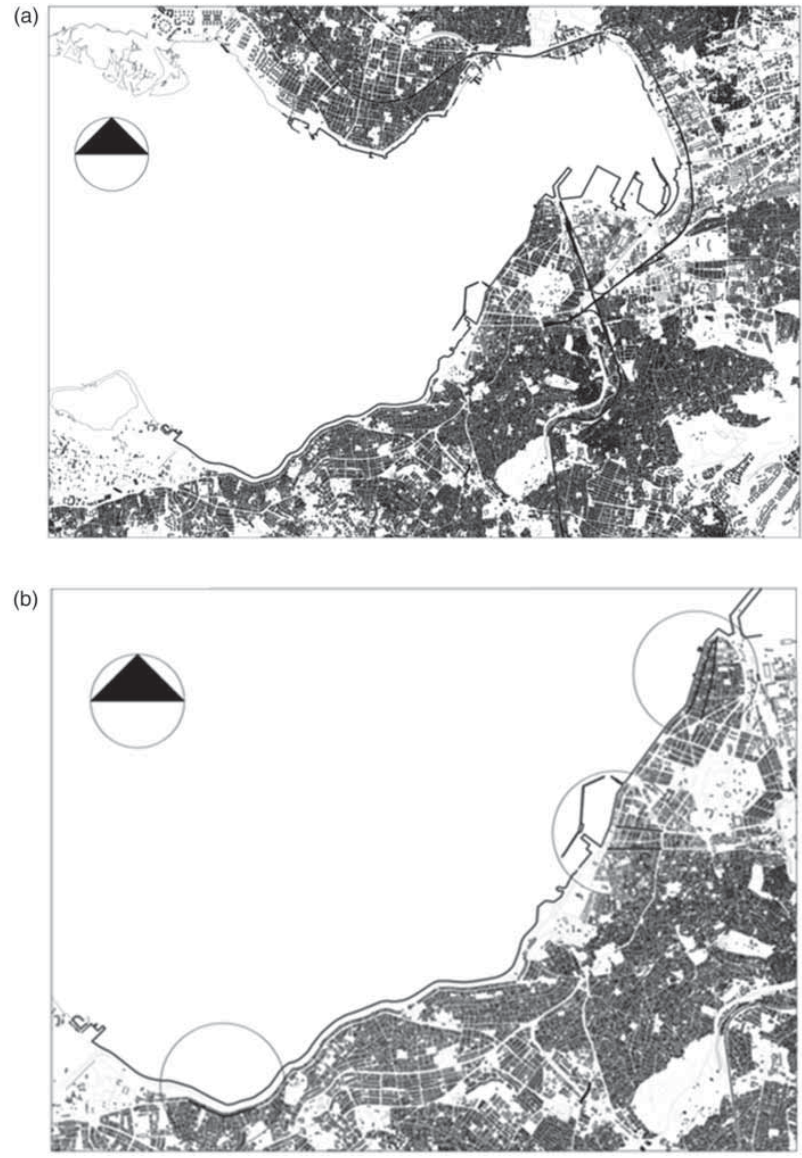

Figure 1. (a) The location of the field study area and (b) the orientation of the main canyons.
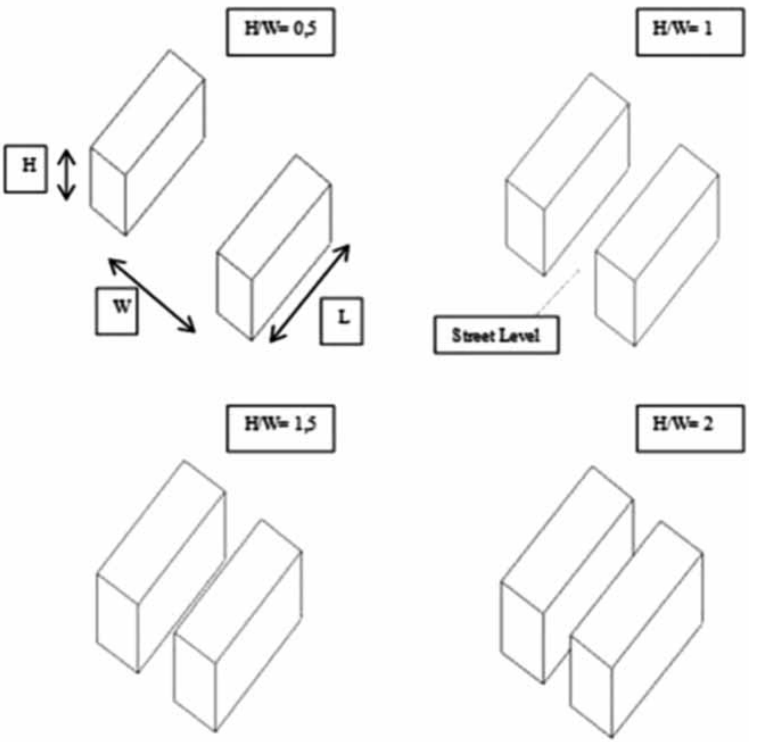

Figure 2. Shallow canyon $(H / W=0.5)$, deep canyon $(H / W=2)$ and $H / W=1, H / W=1.5$ canyons. range of factors are present (Georgakis and Santamouris 2008; Niachou, Livada, and Santamouris 2008a, 2008b; Santamouris, Georgakis, and Niachou 2008; Kitous, Bensalem, and Adolphe 2012). Therefore, in the examination of the results these factors should be taken into consideration.

\section{Literature review \\ UHI effect}

Rapid population growth and industrial activity in cities throughout the world resulted in denser urbanization when compared with the historic cities. As a consequence of heat balance, air temperature in these dense and crowded cities became higher than the surrounding rural environment. This phenomenon is known as the UHI effect (Georgakis and Santamouris 2006). The largest elevations of urban temperatures occur during clear and still-air nights which are called 'nocturnal UHI effect'. These temperature differences reach $3-5^{\circ} \mathrm{C}$ and even $8-10^{\circ} \mathrm{C}$ (Givoni 1998; Santamouris et al. 2001; Karatasou, Santamouris, and Geros 2006). The main reason of the latter is that during night fall, streets are still radiating heat while surrounding rural areas are rapidly cooling (Karatasou, Santamouris, and Geros 


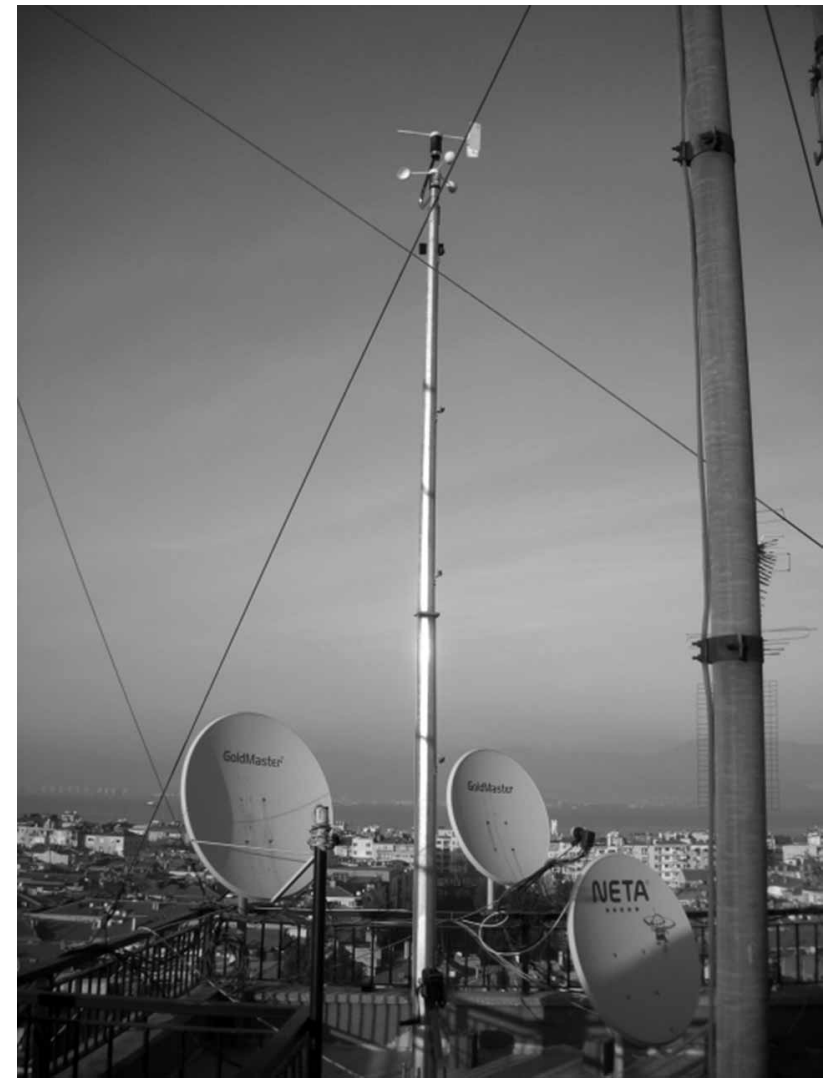

Figure 3. Meteorology station in Güzelyalı (with the permission of Güzelyalı NMO).

2006). The UHI at night provides a warmer environment during winter time. However, during the hot summer periods in the Mediterranean regions, the UHI results in an uncomfortable environment especially for the pedestrians (Tayanç and Toros 1997; Santamouris 2007).

Enhancing the air movement through natural ventilation is one of the dissipation techniques of excess heat generated in urban areas. Airflow around buildings gives the ability to control environmental factors related to temperature, humidity, air motion and contaminants (Santamouris 1998). On the other hand, due to the three-dimensional geometry of urban areas, friction forces on the wind flow, thermal effects, movement of vehicles, etc., the wind speed is either decreased or increased. The decrease in wind speed can be disturbing especially in hot weather conditions. Furthermore, exhaust gases can be trapped in the streets where the wind channelling character of the streets is weak (Yamartino and Wiegand 1986; Ahmad, Khare, and Chaundry 2005; Blocken et al. 2008; Buonanno, Fuoco, and Stabile 2011; Carpentieri et al. 2012). Finding solutions for optimum wind environment in the existing situations is not easy since in modern town planning, streets are mainly planned in response to the requirements of transport systems as well as other factors such as ownership. In addition, orientation of streets with respect to the path of the sun or prevailing wind is rarely considered during the design process, although

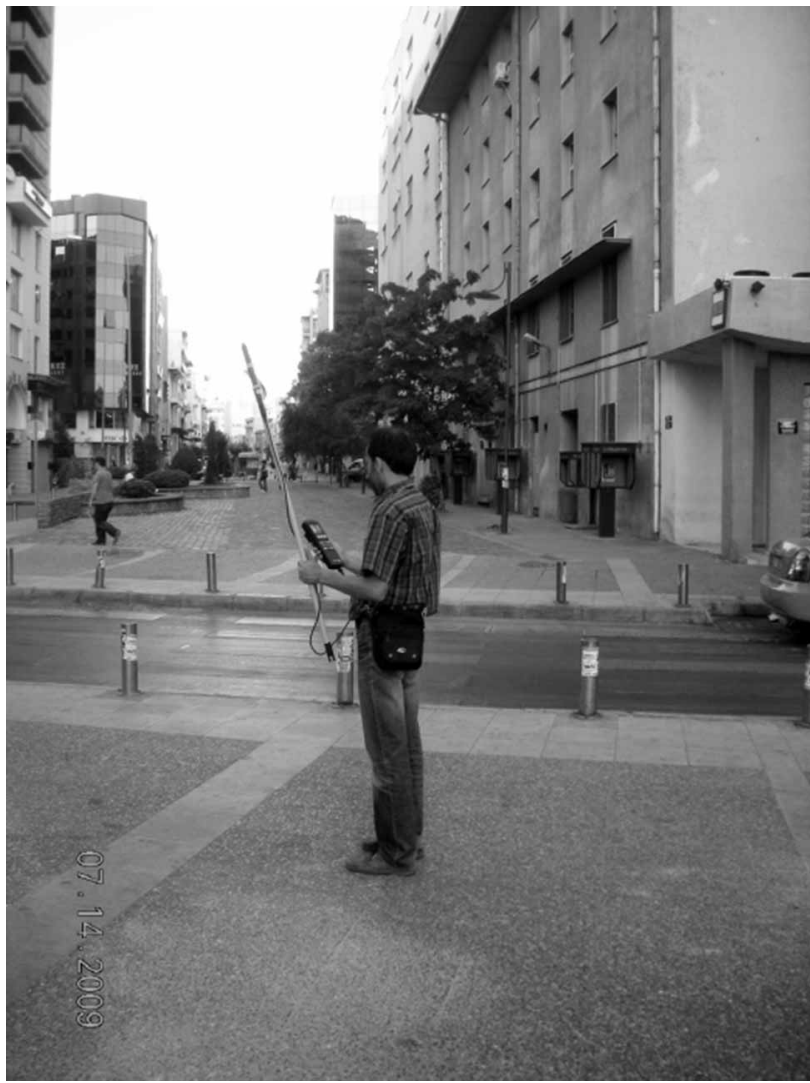

Figure 4. Measurements from $2 \mathrm{~m}$ height (Arkon's archive).

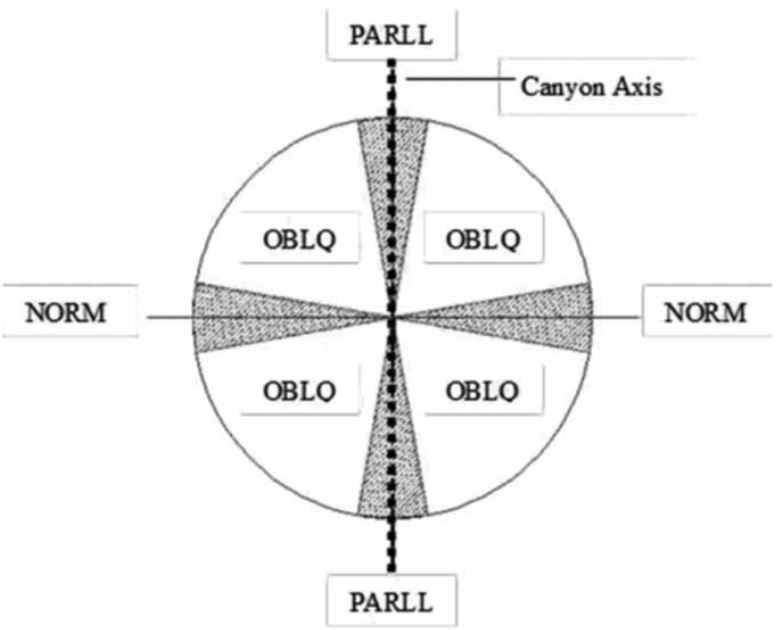

Figure 5. Wind direction angles to the canyon axis: PARLL, OBLQ and NORM.

its effect on microclimate was recognized throughout the history of many cities (Kenworthy 1985; Erell 2008).

\section{The effect of buildings on wind environment}

Space bound by urban buildings up to their roofs is often referred to as the 'urban canopy' and the volume of air 
(a)

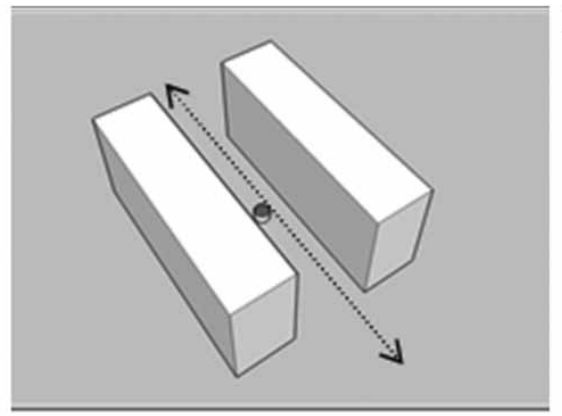

(c)

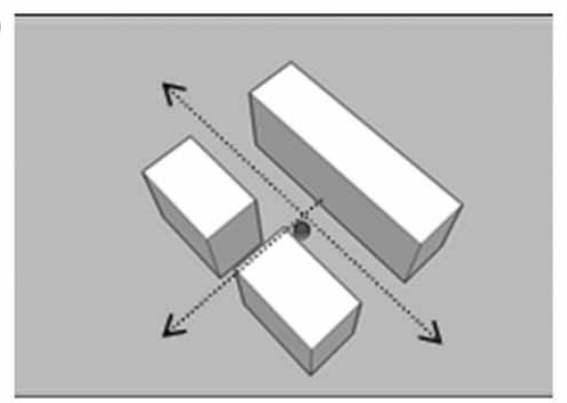

(e)

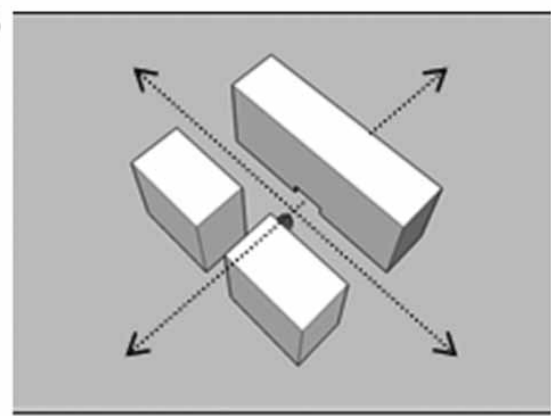

(b)

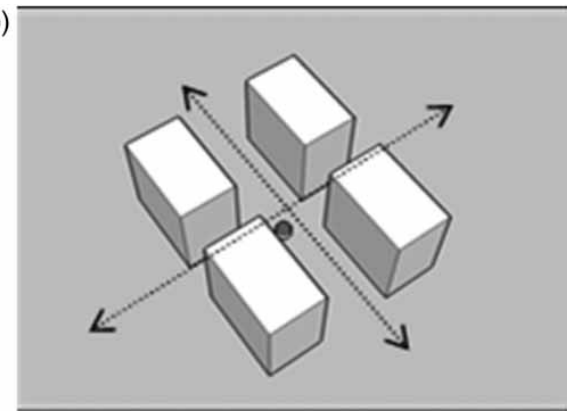

(d)

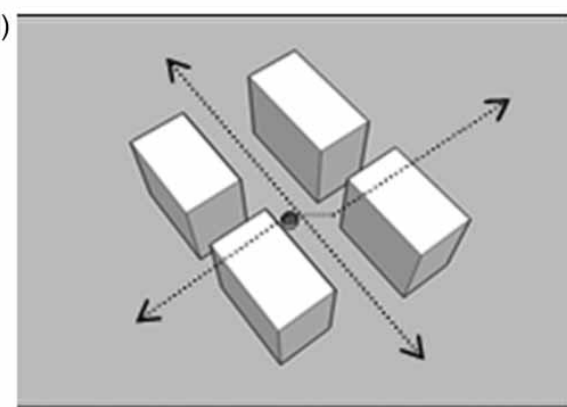

(f)

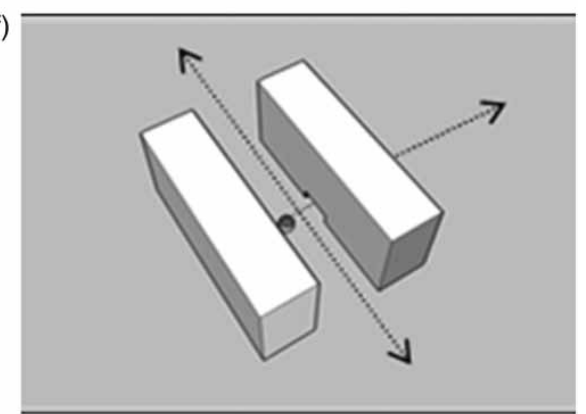

Figure 6. (a) CLSD: closed; (b) CRSS: cross; (c) TSHP: t-shape; (d) SFTCRSS: shifted-cross; (e) TCRSS: t-cross; (f) PDST pedestrian-level opening.

affected by the city is called the 'urban boundary layer', also known as the 'urban air dome' (Givoni 1998).

Urban wind environment situated in the urban air dome has different characteristics when compared with windflow regime in rural areas. When the wind flows over an open area approaching the boundaries of the built-up open area, it encounters a higher 'roughness' of the surface created by buildings. These deflect the wind upwards, leaving the near-ground locations with much slower wind speeds (Givoni 1998).

On the other hand, wind speed may be increased by the channelling or blocking effect of the buildings, creating a highly turbulent and therefore disturbing flow. Turbulent flows are rather unsteady. The three-dimensional environment creates energetic vortices where the conserved quantities are stirred and mixed violently (Houghton and Carruthers 1976).

In the relevant literature, streets that have special geometric characteristics are called 'street canyons', forming geometries similar to natural canyons. Oke (1988) defines a 'urban street canyon' as the basic geometric unit which can be reasonably approximated by two-dimensional crosssections, neglecting street junctions and assumes that buildings along the canyon axis are semi-infinite in length. Oke then limits geometric descriptors into a simple measure, which is the ratio of $H / W$, where $H$ is the average height of the canyon walls and $W$ is the canyon width. Georgakis and Santamouris (2008) have added another geometrical descriptor defining the slenderness of the street as $L / W$ where $L$ is the length of the canyon (Georgakis and Santamouris 2008).

According to Ahmad, Khare, and Chaundry (2005) the canyon is considered to be uniform if it has an aspect ratio approximately equal to one with no major openings on the walls. A shallow canyon has an aspect ratio $(H / W)$ below 0.5 ; while the aspect ratio 2 represents a deep canyon (Figure 2). When $L / H=3$ it is a short canyon, when $L / H=5$ it is medium and when $L / H=7$ 
(a)

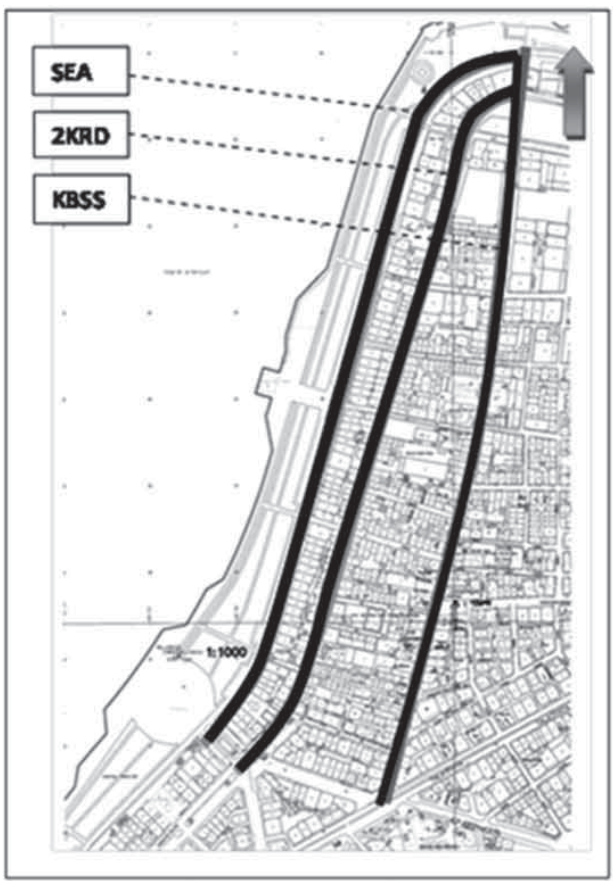

(b)

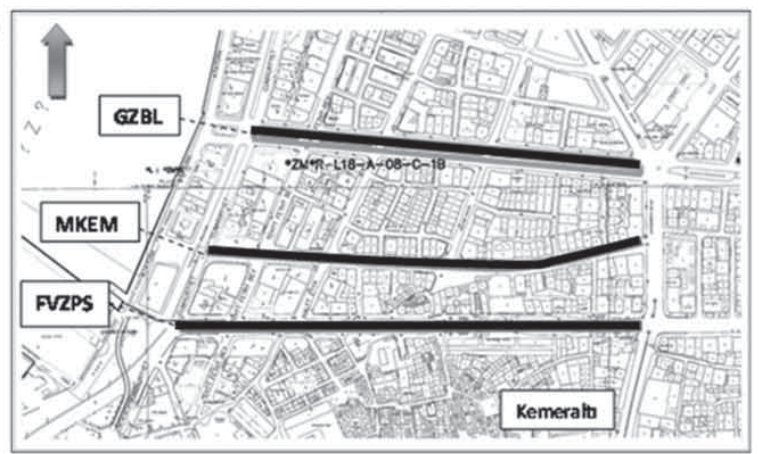

(c)

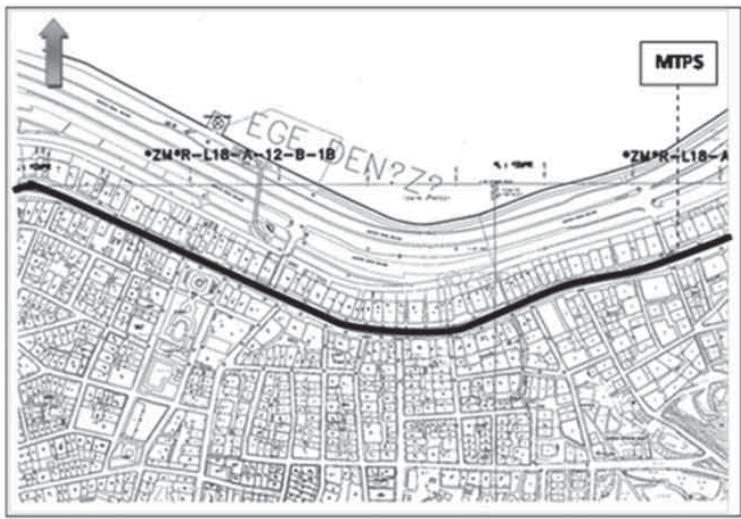

Figure 7. The selected sites of the field study with measured streets (main canyons): (a) Alsancak, (b) Konak, (c) Güzelyalı.

it is considered to be a long canyon (Ahmad, Khare, and Chaundry 2005).

Urban streets are also classified as symmetric and asymmetric canyons, respectively, if the buildings on both sides
Table 1. Characteristics of the main canyons in the selected sites: ALS, KNK and GZYL.

\begin{tabular}{lllll}
\hline Sites & Canyons & $H / W$ & $L / H$ & Orientation \\
\hline AREA & & & & \\
ALS & 2KRD & 1.68 & 45 & NE-SW \\
& KBSS & 1.6 & 41 & NE-SW \\
KNK & GZBL & 0.58 & 22 & E-W \\
& FVZPS & 0.64 & 30 & E-W \\
GZYL & MTPS & 1 & 52 & E-W \\
\hline
\end{tabular}

(a)

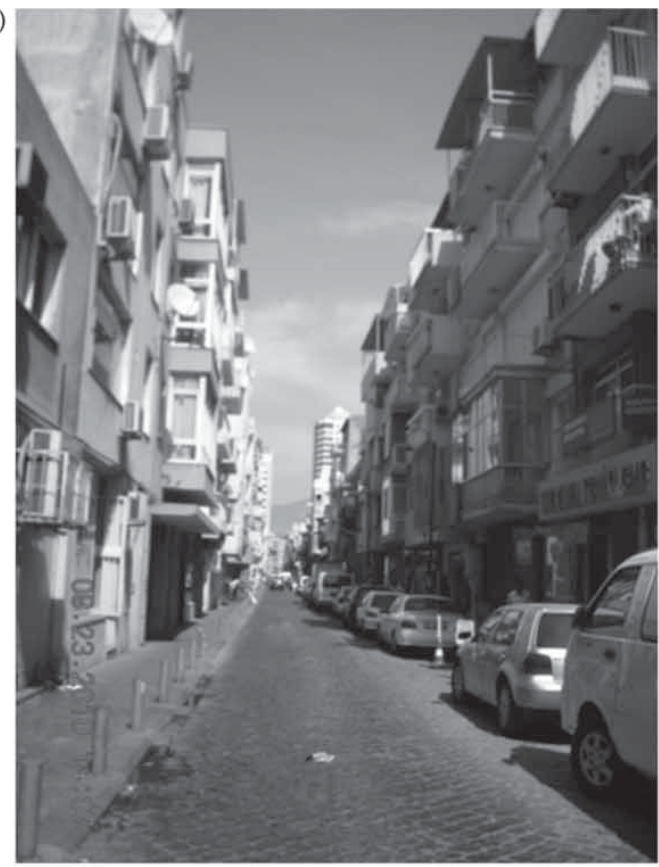

(b)

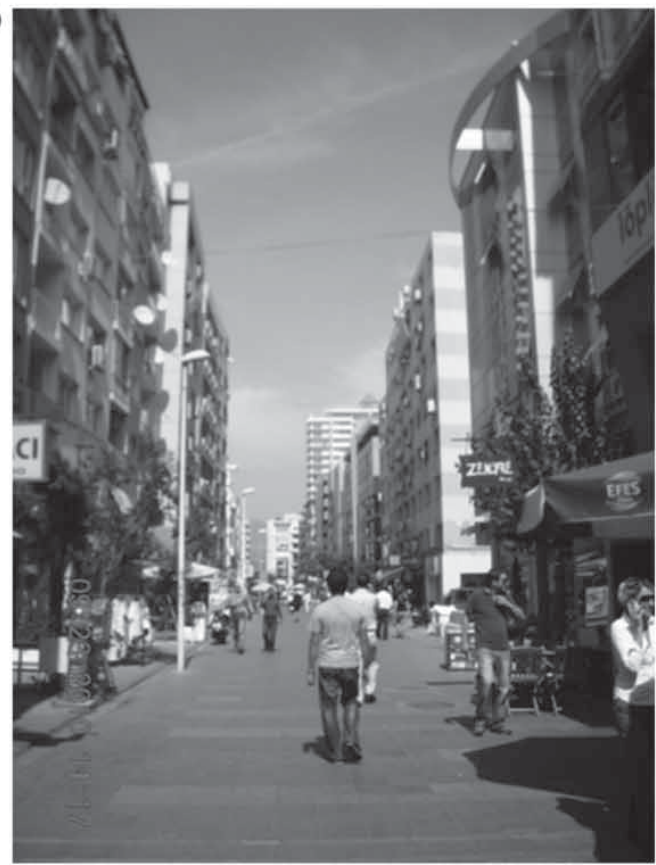

Figure 8. (a) 2KRD and (b) KBSS canyons in Alsancak (Arkon's archive). 

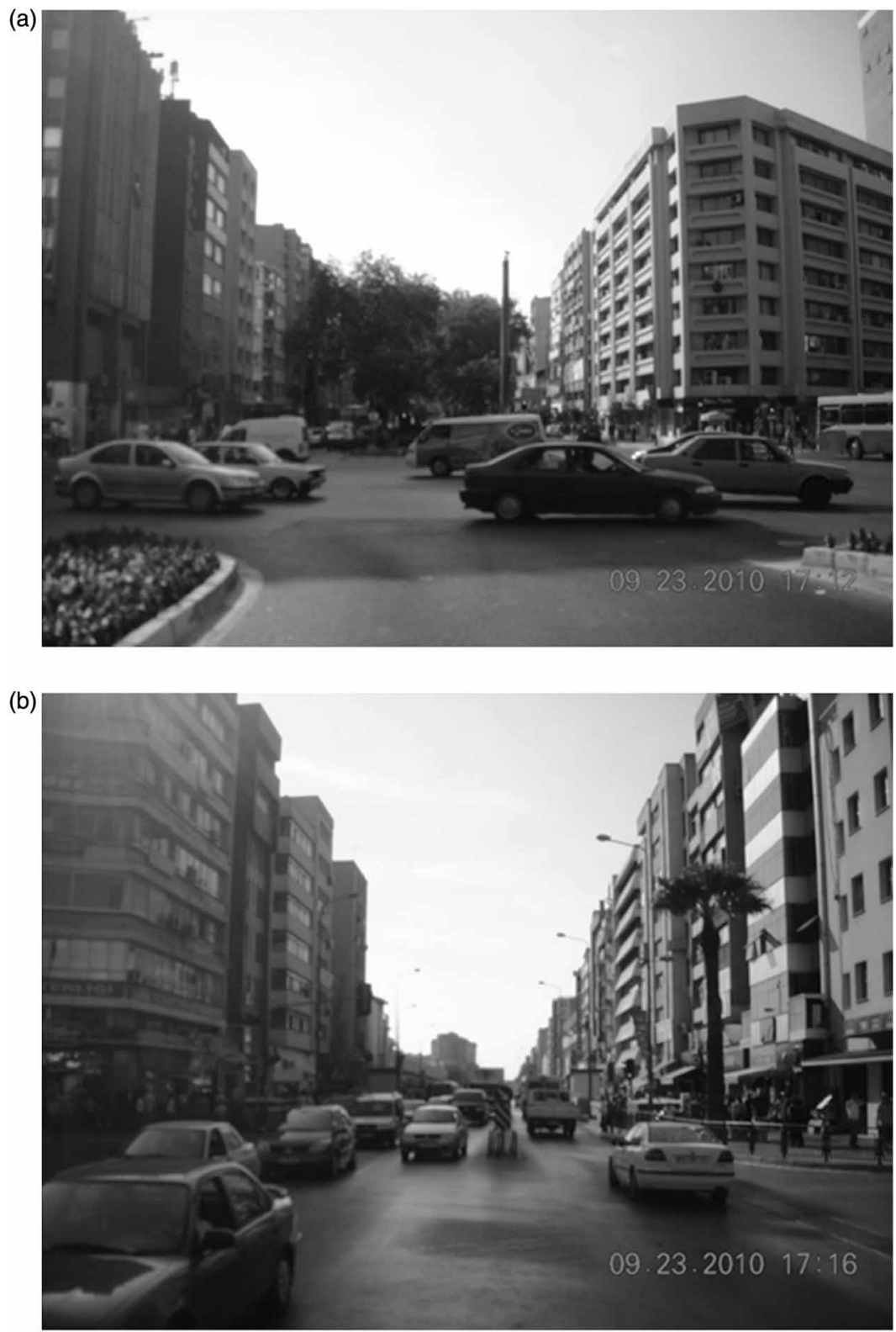

Figure 9. (a) GZBL and (b) FVZPS canyons in Konak (Arkon's archive).

of the street have approximately the same height or if there are significant differences in building height (Georgakis and Santamouris 2006).

According to Georgakis and Santamouris (2008), when $L / W<20$, dominant end effects play an important role on wind speeds inside the canyon. In the same study, when $H / W<0.7$ the street is not considered to be a street canyon. In this study, when $H / W=2$ the street is considered as a deep canyon, when $H / W=0.5$ it is shallow and when $H / W=1$ it is medium.

\section{Wind-flow patterns in urban canyons}

Wind-flow pattern is important in understanding the natural ventilation potential of urban canyons. The upwind angle to the canyon axis has important effects on wind speed at the pedestrian level. In the relevant literature, orientation of the prevailing wind to the canyon axes is categorized into three types: Normal, oblique and parallel (Ahmad, Khare, and Chaundry 2005; Niachou, Livada, and Santamouris 2008a; Santamouris, Georgakis, and Niachou 2008).

When the upwind is normal or perpendicular to the street canyon axis if the spacing between two buildings is too large and the height is comparatively low, their flow fields do not interact $(H / W>0.05)$. Smaller spacing between buildings disrupts the 'wakes', resulting in an 'isolated roughness flow regime'. A higher $H / W$ causes a flow regime change and is known as 'wake interference flow'. At a greater $H / W$, a circulatory vortex is established inside the street canyon (Oke 1988). 

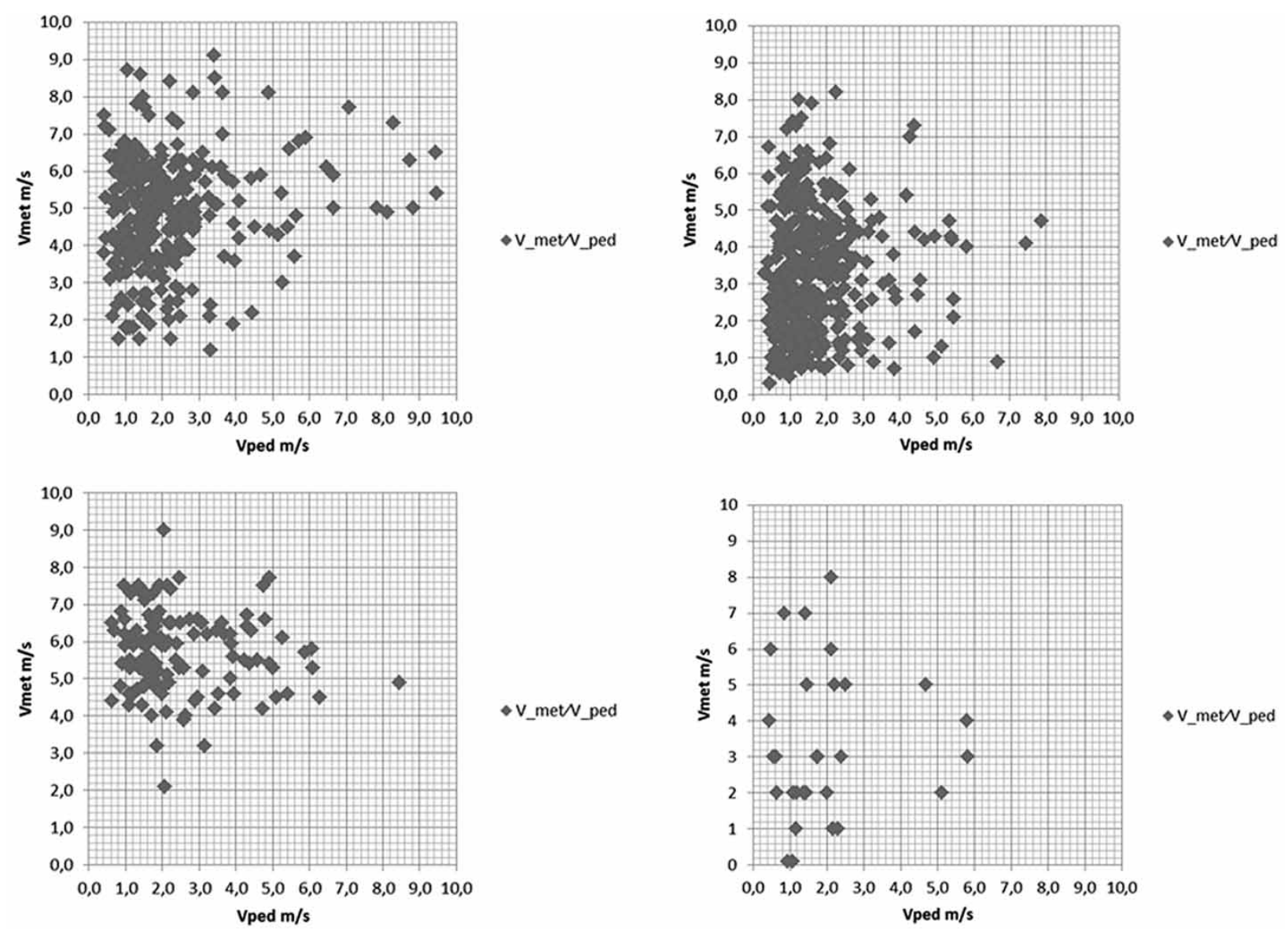

$\diamond V_{-}$met $N \_$ped
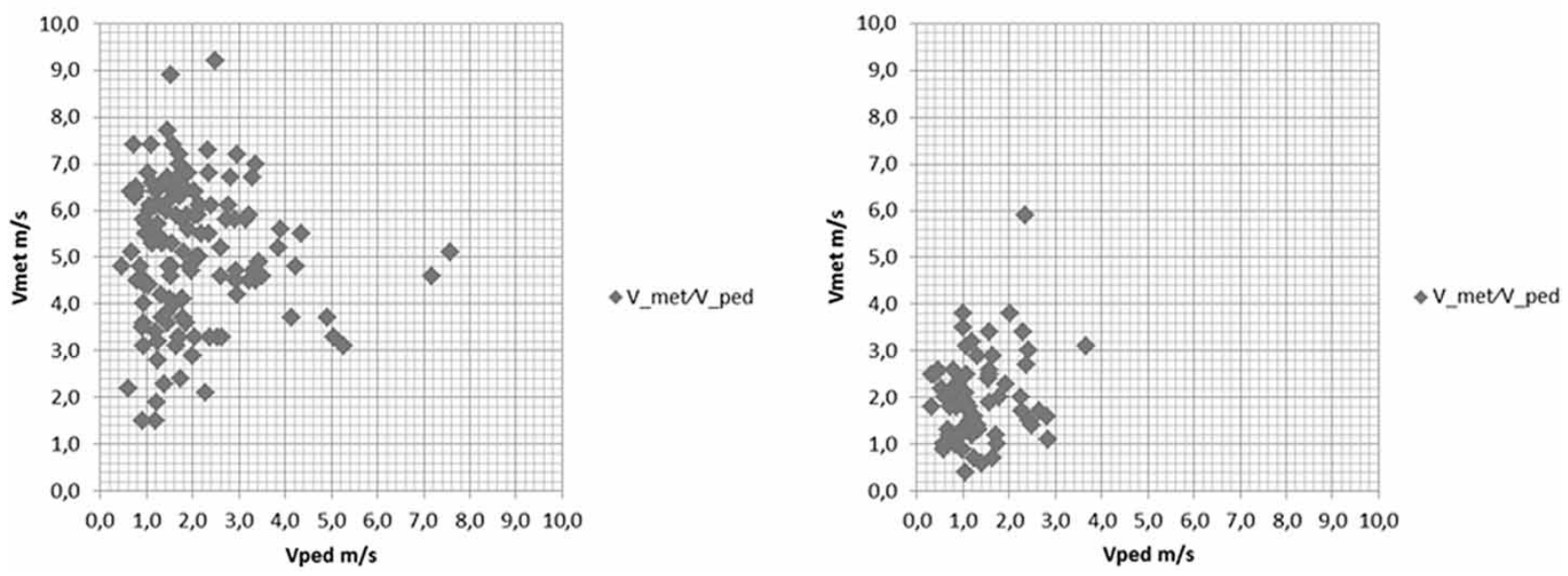

Figure 10. (a) MID and AFT periods $V_{\text {met }} / V_{\text {ped }}$ diagram for oblique wind direction. (b) MID and AFT periods $V_{\text {met }} / V_{\text {ped }}$ diagram for parallel wind direction. (c) MID and AFT periods $V_{\text {met }} / V_{\text {ped }}$ diagram for normal wind direction.

When the wind flow is oblique to the canyon axis, a spiral vortex is developed along the canyon's length. The flow is not perfectly reflected by the building walls (Niachou, Livada, and Santamouris 2008a). In this case, Givoni (1998) suggests widening of the streets in order to improve ventilation conditions both within the buildings and in the streets.

According to Givoni (1998) when the streets are parallel to the direction of the wind, they create obstacle-free passageways, through which the prevailing winds can penetrate into the heart of the urban area. However, in that case the friction between street canyon walls and the surface retards the approaching wind flow (Ahmad, Khare, and Chaundry 2005; $\mathrm{Ng}$ et al. 2011).

By means of several studies it is known that appropriate ventilation through the streets helps in flushing out exhaust gases where there is heavy vehicular traffic. Related literature indicates that when the ambient flow is normal to the 

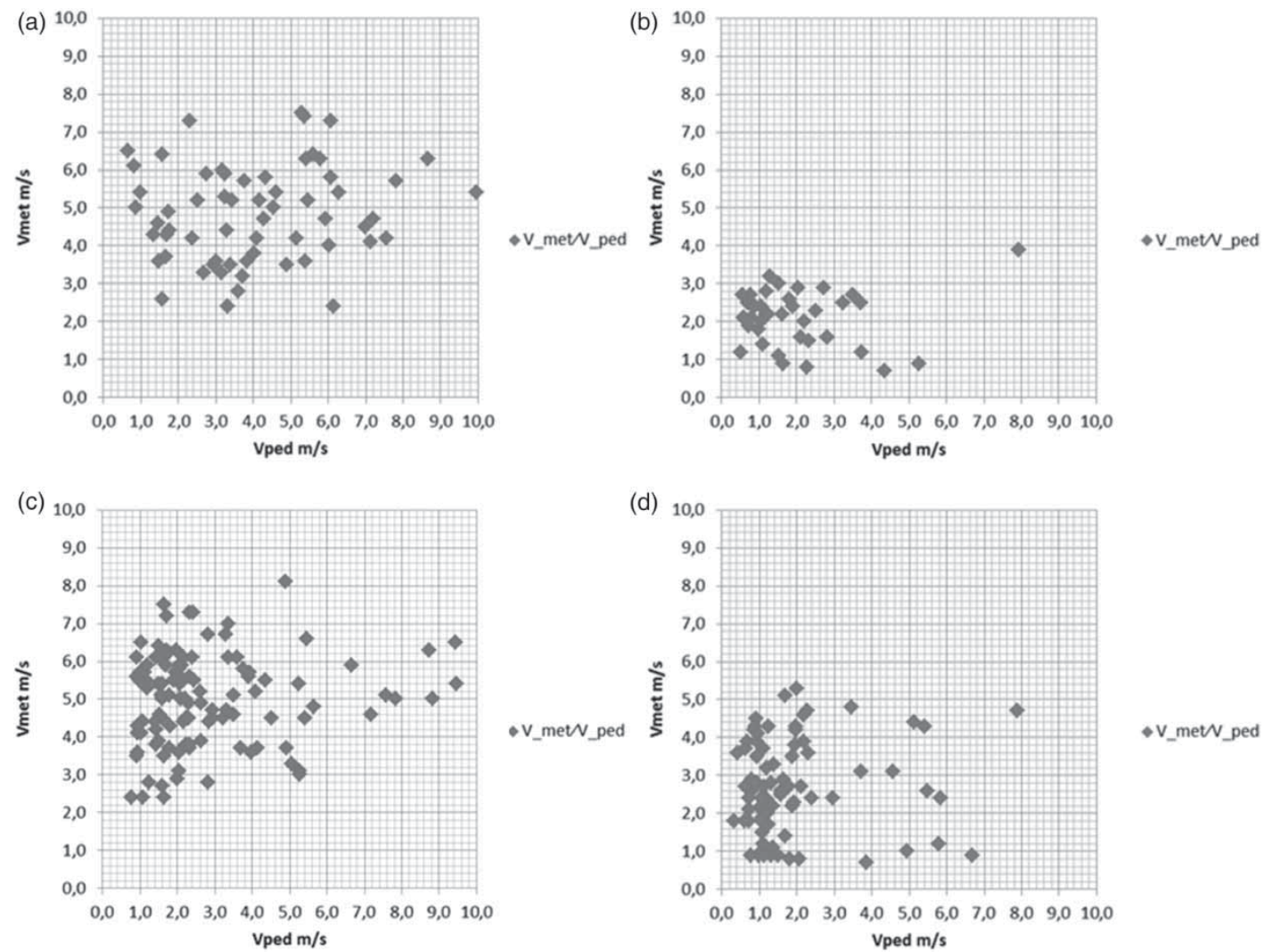

Figure 11. (a) $V_{\text {met }} / V_{\text {ped }}$ diagram on the seaside during MID and AFT periods in Alsancak. (b) $V_{\text {met }} / V_{\text {ped }}$ diagram in $2 \mathrm{KRD}$ canyon during MID and AFT periods in Alsancak.

canyon axis, highest pollutant concentrations were found in the canyon (Ahmad, Khare, and Chaundry 2005; Buonanno, Fuoco, and Stabile 2011; Moonen et al. 2012).

According to Kitous, Bensalem, and Adolphe (2012), street length influences the flow intensity: horizontal flow is more important in a low compact street canyon than in a shorter and shallower one. Even for the oblique upwind conditions the flow in the long street is two dimensional. On the other hand, in the short street canyon the wind directions vary between oblique and parallel to the street axis even with the perpendicular upwind. In addition, the street length has less effect on the airflow mechanisms in an asymmetric and a long street canyon than in a symmetric street (Kitous, Bensalem, and Adolphe 2012).

According to Ng et al. (2011), after Computational Fluid Dynamics and wind tunnel studies for Hong Kong it was concluded that interconnectivity of open spaces for better urban ventilation is necessary. In order to allow effective air movements into the urban area to remove heat, gases and particulates and to improve the microclimate of the urban environment, breezeways or air paths should be intersected. Breezeways can be formed by principal roads, interlinked open spaces, amenity areas, non-building areas, building setbacks and low-rise building corridors. These air paths should be linked so as to enhance wind penetration in urban areas and should be perpendicular or at an angle to each other and extend over a sufficiently long distance for continuity (Ng et al. 2011). Cross-type street intersections have potential to channel the wind inland.

\section{Field study}

The pedestrian level wind velocity and the upwind velocity data were gathered from three sources in order to make a comparative study:

- NMO, situated in Güzelyalı District, where wind measurements were taken at $29 \mathrm{~m}$ height (Figure 3).

- Data on wind speed from the streets were collected at the pedestrian level at approximately $2 \mathrm{~m}$ height (Figure 4) by TESTO 400 Multifunctional devices (2 TESTO 400 multifunctional devices with 2 hot bulb probes with a measurement range of $0-10 \mathrm{~m} / \mathrm{s}$ wind speed) taken from specific points in:

- Güzelyalı (GZYL) district in Mithat Paşa Street (MTPS)

- Konak (KNK) district in Gazi Boulevard (GZBL) and Fevzi Paşa Boulevard (FVZPS)

- Alsancak (ALS) district in Kıbrıs Şehitleri Street (KBSS) and İkinci Kordon Street (2KRD)

The upwind direction to the canyon axes is categorized into three classes: Normal (NORM), parallel (PARLL) and oblique (OBLQ) (Figure 5). 

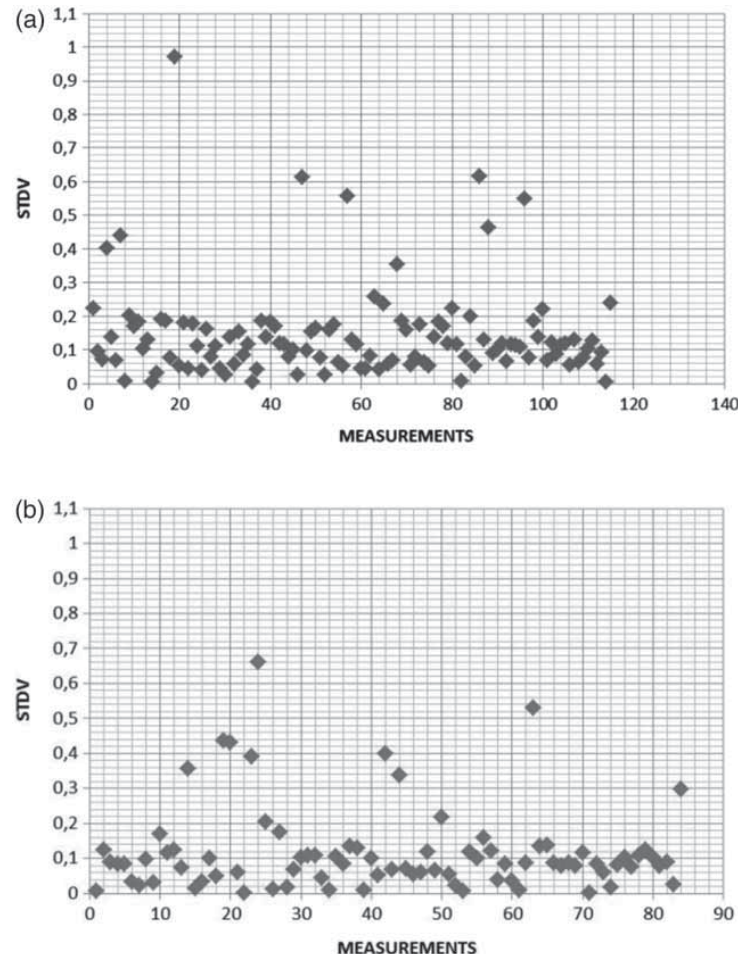

Figure 12. Standard deviations ( $y$-axis) of pedestrian-level wind velocities around the mean value in the $2 \mathrm{KRD}$ canyon during MID and AFT periods.

In Figure 5 hatched areas represent $20^{\circ}$ intervals for the wind flowing NORM or PARLL to the main canyon axis. Therefore, for $70^{\circ}$ intervals the wind direction to the canyon is considered OBLQ.

The main canyons were first categorized according to $H / W$ ratio as $0<H / W \leq 1$ and $1<H / W$.

Two measurement periods were taken at midday (MID) and afternoon (AFT), including the time period when the sun sets. The MID period is roughly between 13:00 and 16:00 hours, including the highest position of the sun. The AFT period has been accepted to be between 19:00 and 22:00 hours including the sunset period, when the UHI is considered as higher: ambient temperature drops and energy stored in the building masses is reradiated to the surrounding air.

Pedestrian-level measurements were taken from each measurement point, classified by two-dimensional geometrical characteristics as CLSD (closed), CRSS (cross), SFTCRSS (shift-cross), TSHP (t-shape), TCRSS (t-cross) and PDST (pedestrian-level opening) as shown in Figure 6. A measurement duration of one minute was used in the field study with a measurement period of $10 \mathrm{~s}$ in which the average of seven measurements was taken for each sample. The cross-type point is considered as the most appropriate junction type because of its potential to interconnect the streets and open spaces and channel the wind through these areas.

Main canyons in Figure 7 were selected according to their geometrical characteristics listed in Table 1.
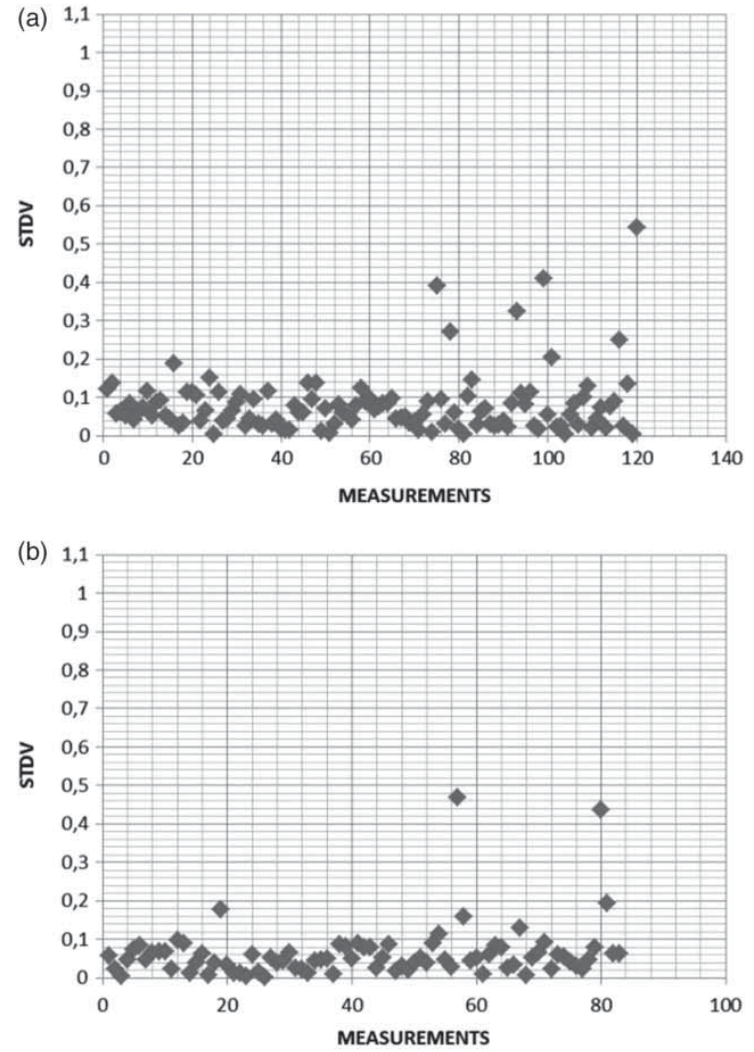

Figure 13. Standard deviations ( $y$-axis) of pedestrian-level wind velocities around the mean value in the KBSS canyon during MID and AFT periods.

Street canyons in Alsancak have the highest aspect ratios of $H / W$ and $L / H$ among the others; in other words they are the deepest canyons (Figure 8(a) and 8(b)) but shorter than the street canyon in Güzelyali. In Konak, two parallel canyons are shallow and shorter than the others; especially Fevzi Paşa Bulvarı (FVZPS) has an asymmetric part near the seaside (Figure 9(b)).

\section{Results of the field study}

The field study was held in July, August and September 2009: two different consecutive three days in July, consecutive three days in August and in September in five main canyons and numerous secondary canyons intersecting with the main canyons.

According to the wind speed and direction data obtained from NMO, during the MID periods western wind with an average wind velocity of $6 \mathrm{~m} / \mathrm{s}$ is apparent. In the MID measurement periods in KNK and GZYL a combination of northern and western winds can be noticed. In the AFT periods the wind pattern is more scattered in terms of average speed and direction. Especially in KNK and GZYL data are concentrated in the NE direction, with an average wind velocity of $6 \mathrm{~m} / \mathrm{s}$. On the other hand, in ALS it is in the North direction. 

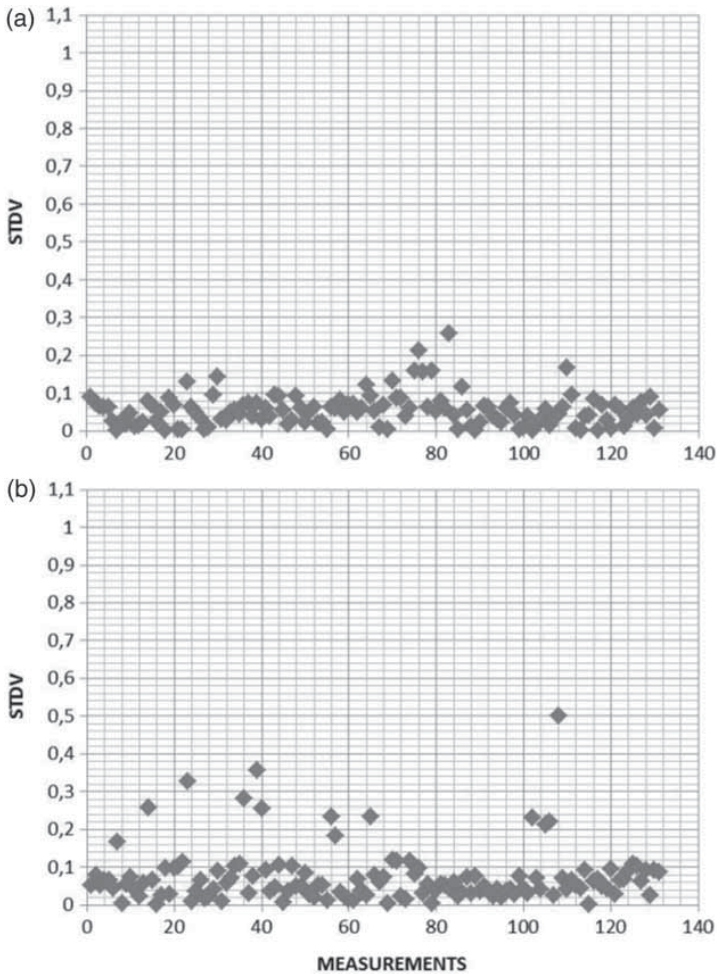

Figure 14. Standard deviations ( $y$-axis) of pedestrian-level wind velocities around the mean value in the MTPS canyon during MID and AFT periods.
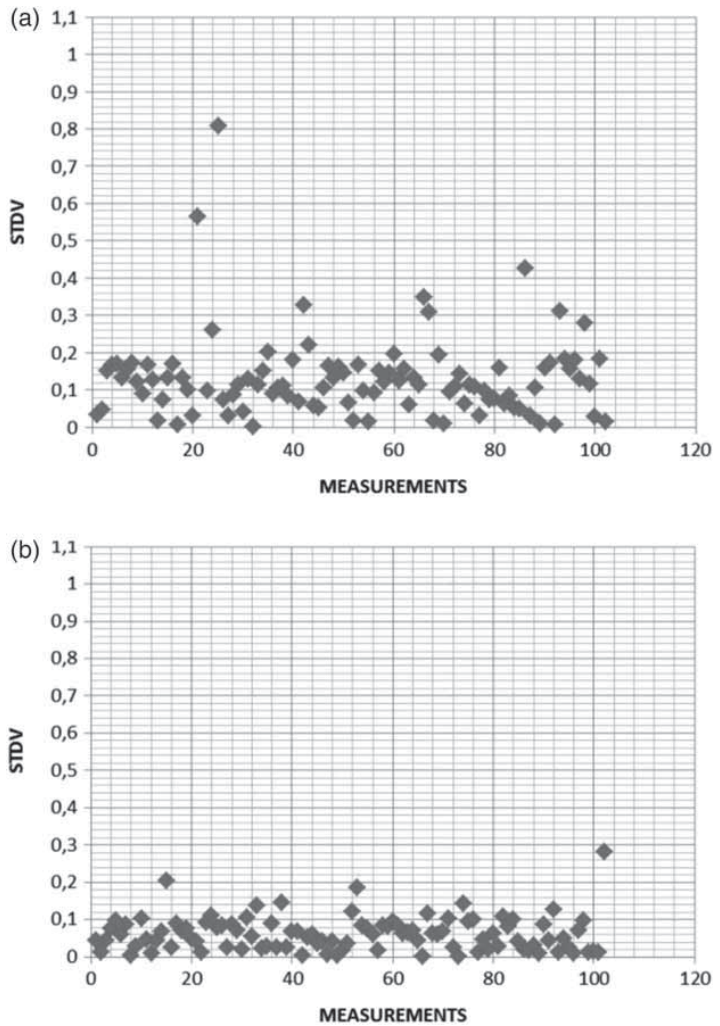

Figure 15. Standard deviations ( $y$-axis) of pedestrian-level wind velocities around the mean value in the FVZPS canyon during MID and AFT periods.
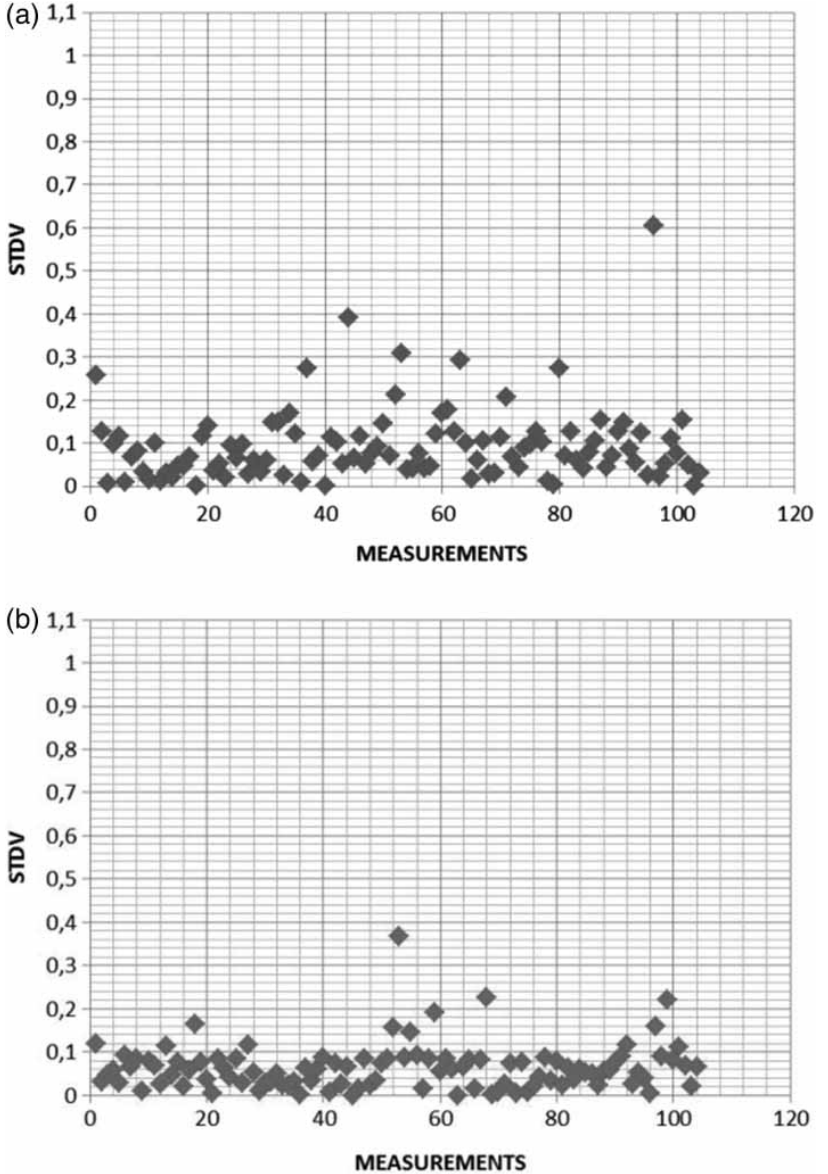

Figure 16. Standard deviations ( $y$-axis) of pedestrian-level wind velocities around the mean value in the GZBL canyon during MID and AFT periods.

\section{The relation coefficient $V_{\text {met }} / V_{\text {ped }}$}

The relation coefficient between the average wind speed measured by the Meteorology Office $\left(V_{\text {met }}\right)$ and the average wind speed measured at the pedestrian level $\left(V_{\text {ped }}\right)$ are measured as:

$$
\begin{aligned}
& V_{\text {met }}=2.1 V_{\text {ped }} \text { for the main canyons } \\
& V_{\text {met }}=2.4 V_{\text {ped }} \text { for the secondary canyons }
\end{aligned}
$$

Therefore, at the pedestrian level, the street canyon effect of the selected street canyons decreases the upwind velocity approximately by half. And in the secondary streets crossing the main streets, the upwind velocity is more than two times that of the pedestrian-level wind velocity.

\section{The effect of upwind velocity on the pedestrian-level wind velocity}

After the measurements it was realized that during the field study the upwind was mainly flowing in the oblique direction to axes of all main canyons: The upwind direction is oblique to the canyon axis in $52 \%$ of the measurements in the daytime periods, while in the afternoon periods, this 
(a)

10,0

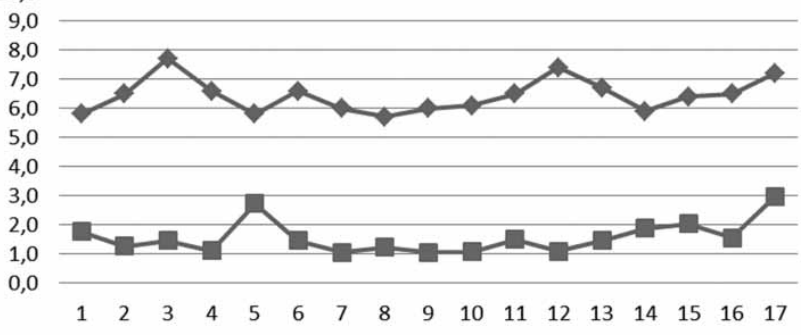

$\rightarrow$ Vmet m/s $\rightarrow$-Vped $\mathrm{m} / \mathrm{s}$

(b)

\section{GZBL-normal}

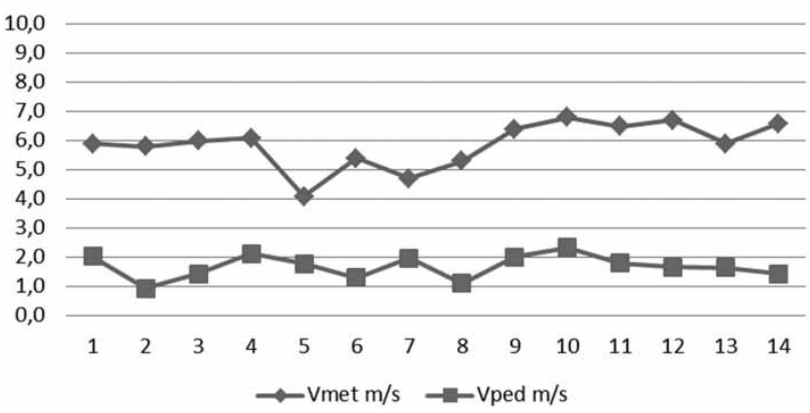

Figure 17. Measurements in the sea-land direction in (a) FVZPS and (b) GZBL in July, MID period under normal upwind direction: $V_{\text {met }}$ and $V_{\text {ped }}(y$ axis), the measurement order of the points ( $x$ axis).

(a)

FVZPS-parallel

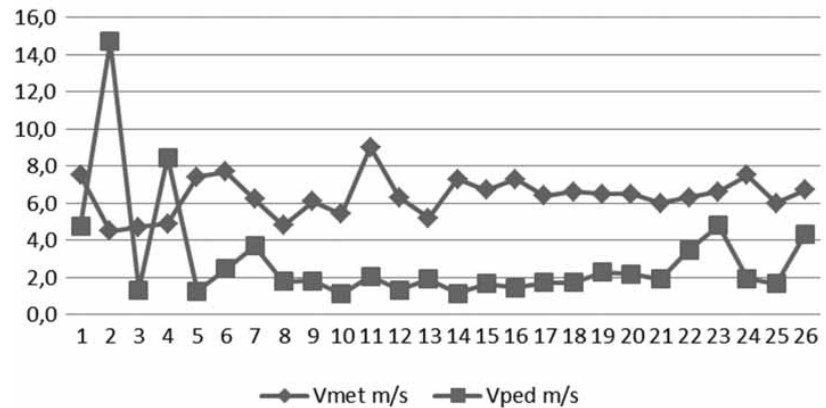

(b)

\section{GZBL-parallel}

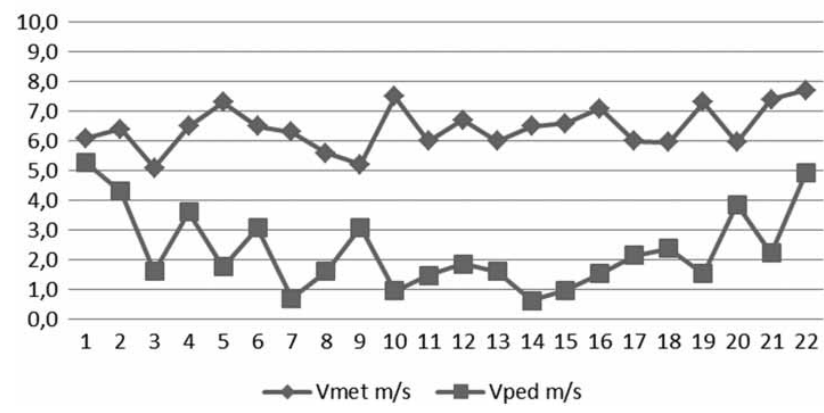

Figure 18. Measurements in the sea-land direction in (a) FVZPS and (b) GZBL in August, MID period under parallel upwind direction: $V_{\text {met }}$ and $V_{\text {ped }}(y$-axis), the measurement order of the points $(x$-axis). (a) FVZPS-parallel

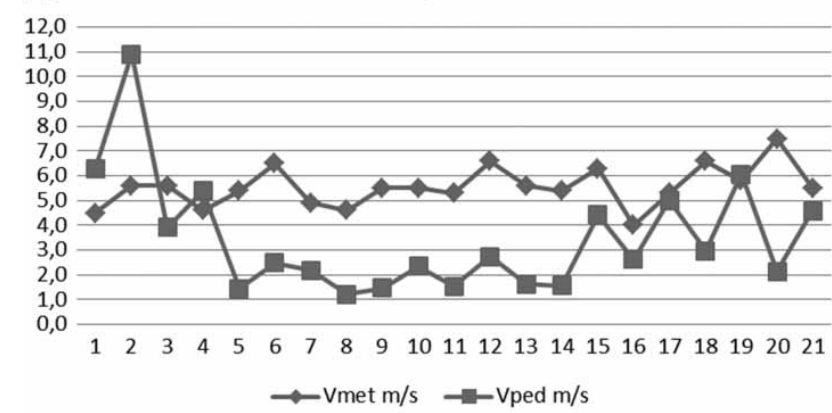

(b)

GZBL-parallel

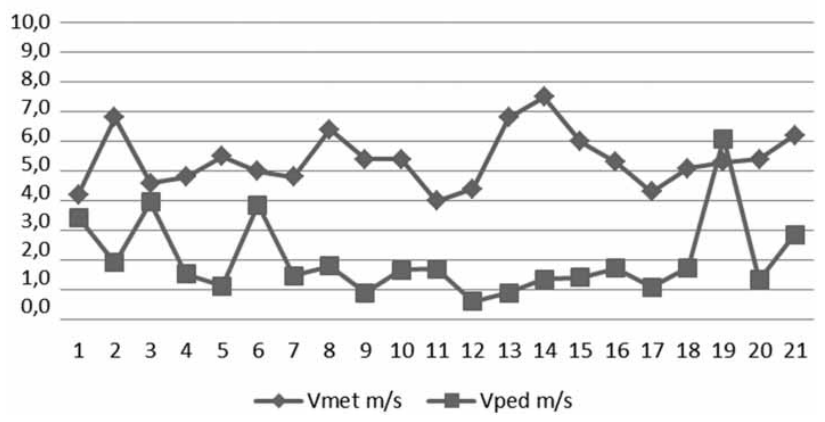

Figure 19. Measurements in the sea-land direction in (a) FVZPS and (b) GZBL in September, MID period under parallel upwind direction: $V_{\text {met }}$ and $V_{\text {ped }}(y$-axis), the measurement order of the points ( $x$-axis).
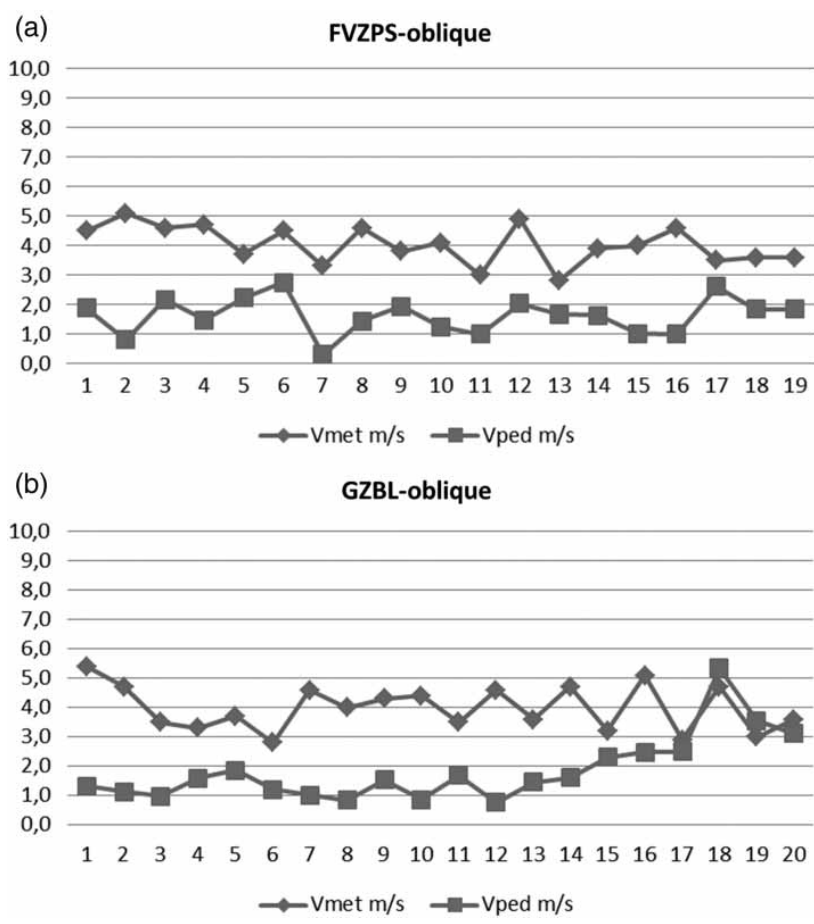

Figure 20. Measurements in the sea-land direction in (a) FVZPS and (b) GZBL in July, AFT period under oblique upwind direction: $V_{\text {met }}$ and $V_{\text {ped }}(y$-axis), the measurement order of the points $(x$-axis). 
(a)

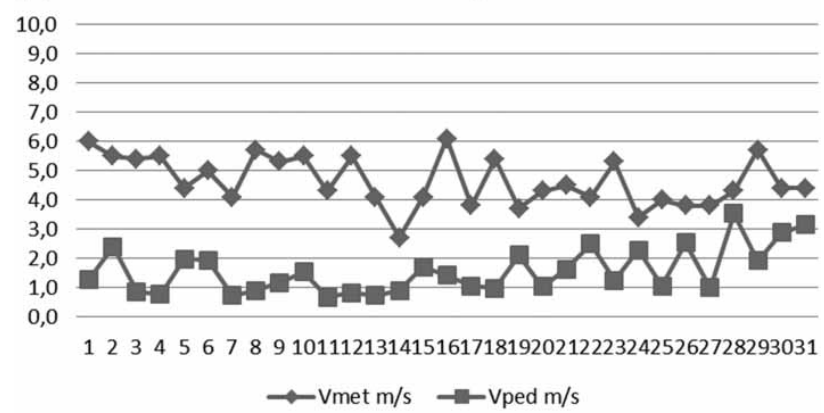

(b)

GZBL-oblique

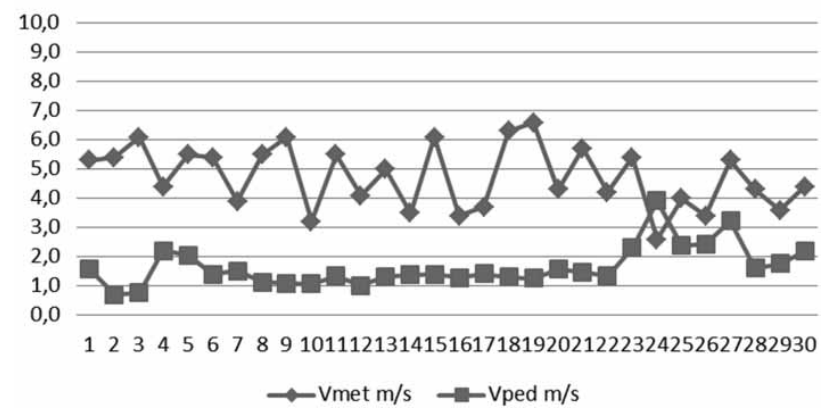

Figure 21. Measurements in the sea-land direction in (a) FVZPS and (b) GZBL in August in AFT period under oblique upwind direction: $V_{\text {met }}$ and $V_{\text {ped }}$ ( $y$-axis), the measurement order of the points $(x$-axis).
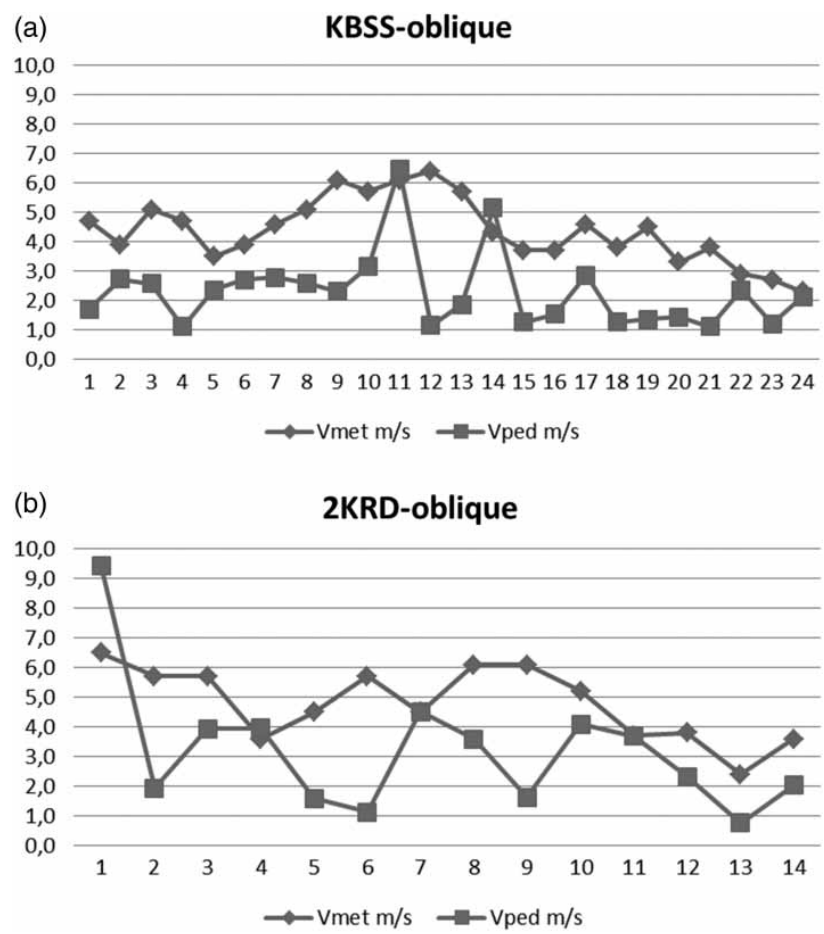

Figure 22. Measurements in the north-south direction in (a) KBSS and in (b) 2KRD in July, MID period under oblique upwind direction: $V_{\text {met }}$ and $V_{\text {ped }}$ ( $y$-axis), the measurement order of the points ( $x$-axis).

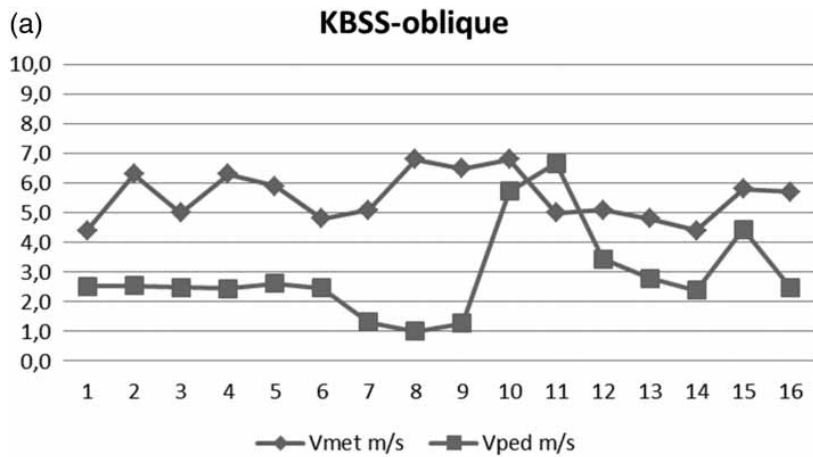

(b) 2KRD-oblique

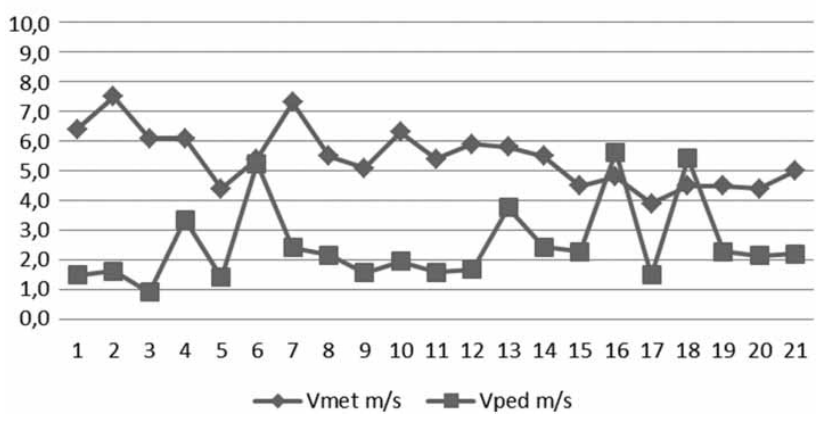

Figure 23. Measurements in the north-south direction in (a) KBSS and (b) 2KRD in August in MID period under oblique upwind direction: $V_{\text {met }}$ and $V_{\text {ped }}$ ( $y$-axis), the measurement order of the points ( $x$-axis).

figure rises up to $80 \%$ (23\% PARLL and $25 \%$ NORM in MID; 6\% PARLL and 14\% NORM in AFT).

- For the main canyons where FVZPS, GZBL, MTPS, 2KRD and KBSS in Konak, Güzelyalı and Alsancak:

Scatter diagrams of $V_{\text {met }}$ on the $y$-axis, $V_{\text {ped }}$ on the $x$-axis for oblique, parallel and normal wind direction to the main canyon axes are represented in Figure 10(a)-(c).

When the upwind is oblique during the daytime (MID period) and afternoon (AFT period) measurements in all canyons under the oblique upwind direction, two distinct clusters of data can be seen (Figure 10(a)) in both time periods: $0.5 \mathrm{~m} / \mathrm{s}<V_{\text {ped }}<3 \mathrm{~m} / \mathrm{s}$ for $1 \mathrm{~m} / \mathrm{s}<V_{\text {met }}<9 \mathrm{~m} / \mathrm{s}$. and $3 \mathrm{~m} / \mathrm{s}<V_{\text {ped }}<10 \mathrm{~m} / \mathrm{s}$ for $1 \mathrm{~m} / \mathrm{s}<V_{\text {met }}<10 \mathrm{~m} / \mathrm{s}$. The second group represents 50\% CRSS- and SFTCRSStype points. In the AFT period, the first group is $0 \mathrm{~m} / \mathrm{s}<$ $V_{\text {ped }}<3 \mathrm{~m} / \mathrm{s}$ for $1 \mathrm{~m} / \mathrm{s}<V_{\text {met }}<7 \mathrm{~m} / \mathrm{s}$, the second group is $3 \mathrm{~m} / \mathrm{s} \leq V_{\text {ped }}<8 \mathrm{~m} / \mathrm{s}$ for $0.5 \mathrm{~m} / \mathrm{s}<V_{\text {met }}<7.5 \mathrm{~m} / \mathrm{s}$. In the second group of afternoon period $56 \%$ of the points are CRSS \& SFTCRSS type and 44\% represents the other types. In other words, for oblique wind in more than half of the pedestrian-level measurements equal to or over $3 \mathrm{~m} / \mathrm{s}$, the measurement is taken from a cross-type street junction.

When the upwind is parallel to the canyon axes, the data are more distributed compared with the oblique direction (Figure 10(b)). Figure 10(c) represents the normal upwind 


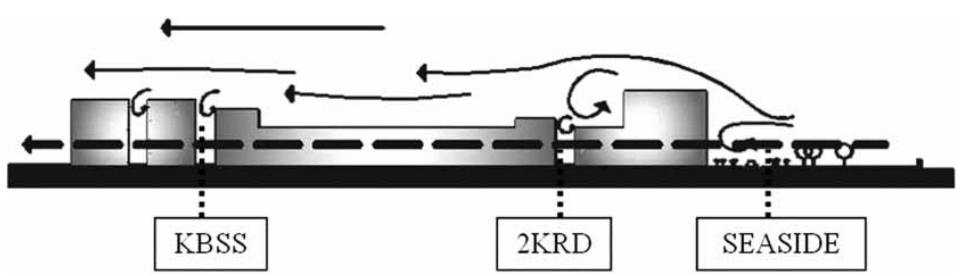

Figure 26. Cross-section from ALS normal to the seaside E-W direction in Alsancak.

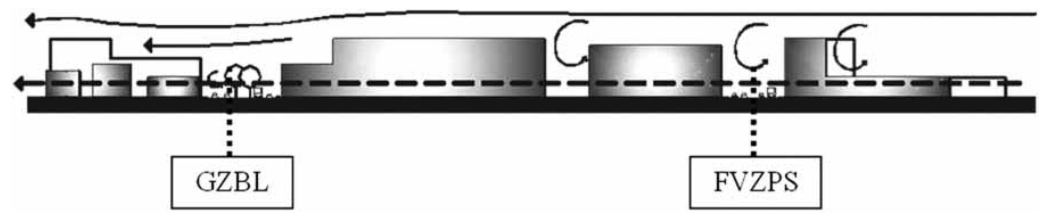

Figure 27. Cross-section from KNK, normal to the main canyons, parallel to the seaside in the N-S direction.

direction to the main canyon axes. In the latter the upwind velocity is higher during the MID period compared with the AFT period. When $3 \mathrm{~m} / \mathrm{s} \leq V_{\text {ped }}, 58 \%$ of the points are CRSS-type points.

- Comparison of seaside and parallel canyon measurements in Alsancak:

The wind shadow effect of the first row of buildings was investigated through the $V_{\text {met }} / V_{\text {ped }}$ ratio measurements. $2 \mathrm{KRD}$ is the first parallel street canyon to the seaside (Figure 11(a) and 11(b)).

In Figure 11(b) during both time periods two distinct clusters of data are apparent due to the wind shadow effect of the buildings on the first row: when $2 \mathrm{~m} / \mathrm{s}<V_{\text {met }}<8 \mathrm{~m} / \mathrm{s}$, $V_{\text {ped }}$ is still approximately between $0.5 \mathrm{~m} / \mathrm{s}$ and $3 \mathrm{~m} / \mathrm{s}$.

\section{Standard deviation of pedestrian-level wind velocity ( $V_{\text {ped }}$ in each canyon}

Five street canyons (2KRD, KBSS, MTPS, FVZPS and GZBL) are evaluated according to the standard deviations around the mean pedestrian-level wind velocity $\left(V_{\text {ped }}\right)$ in MID and AFT time periods (Figures 12-16). These variations around the mean velocities are considered to be affected mainly by upwind velocity and direction to the main canyon axes, the aspect ratio $(H / W)$, the percentage of cross-type points, and the proximity and orientation to the seaside.
In Alsancak, the mean standard deviation of the pedestrian-level wind velocity measurements in the first parallel canyon (2KRD) to the seaside during the daytime period is 0.14 while the same value is 0.08 in the second canyon (KBSS) (Figures 12 and 13). In both time periods (MID and AFT) in two canyons the wind direction in mainly oblique to the canyon axes. Due to its proximity to the seaside at the pedestrian level of the first canyon the wind speed fluctuations are higher than the second one. In addition, 2KRD has vehicular traffic and its parallel canyon KBSS is pedestrian crossed by vehicular roads. On the other hand, in Güzelyalı the main canyon which is parallel to the seaside the mean value of pedestrian-level wind velocity is lower than in Alsancak although the upwind velocity is $4.99 \mathrm{~m} / \mathrm{s}$ and $4.78 \mathrm{~m} / \mathrm{s}$ while in Güzelyalı the same value is $4.47 \mathrm{~m} / \mathrm{s}$. The mean standard deviation for MTPS is 0.06 in MID and 0.08 in AFT periods (Figure 14). The pedestrianlevel mean wind velocities in Alsancak are $2.89 \mathrm{~m} / \mathrm{s}$ and $2.19 \mathrm{~m} / \mathrm{s}$ in the first and second canyons and $1.5 \mathrm{~m} / \mathrm{s}$ in the main canyon in Güzelyalı with oblique upwind directions. Compared with the conditions in Güzelyalı, in Alsancak there are more cross-type junctions formed by continuous streets connected to the seaside which contribute to the pedestrian-level wind velocity. In Alsancak, 39-43\% of the measurements are from cross-type points while the same percentage in Güzelyalı is $21 \%$.

Konak has two parallel canyons with lower aspect ratios ( $H / W$ in GZBL and FVZPS are 0.58 and 0.64 ) compared with other canyons. Both canyons are perpendicular to the seaside with mean upwind velocity values of $5.91 \mathrm{~m} / \mathrm{s}$

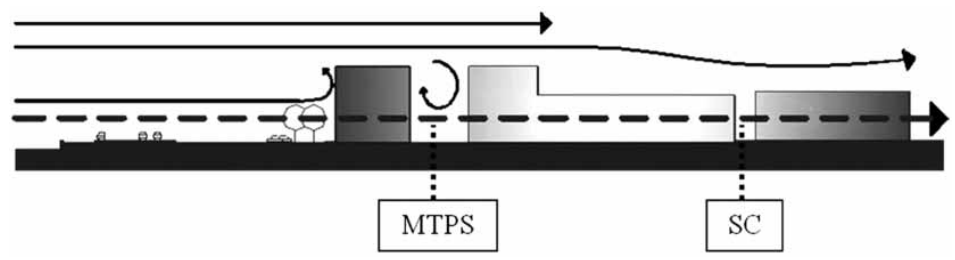

Figure 28. Cross-section from GZYL normal to MTPS, and the secondary canyons (SC) in the N-S direction. 
(a)

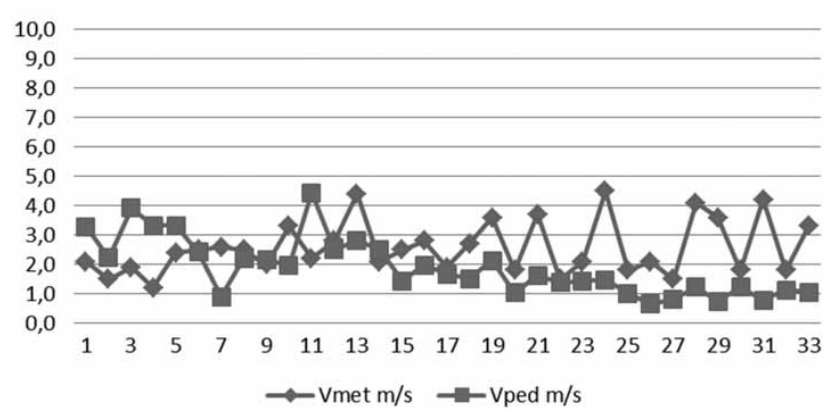

(b) MTPS-oblique

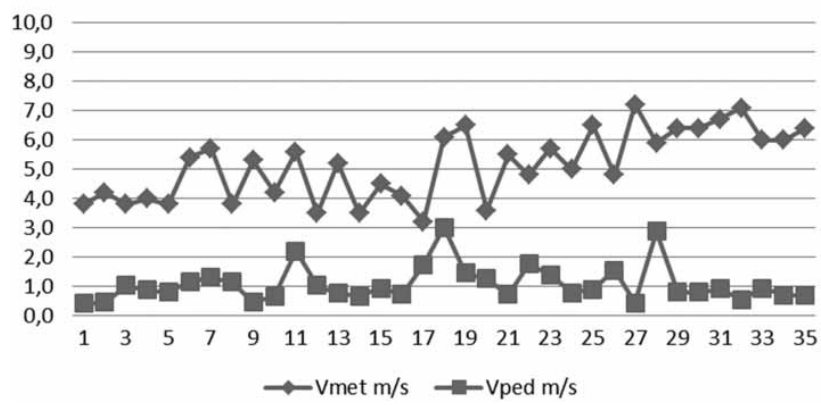

Figure 24. Measurements in MTPS in (a) August and (b) September, MID period under oblique upwind direction: $V_{\text {met }}$ and $V_{\text {ped }}(y$-axis), the measurement order of the points (x-axis).
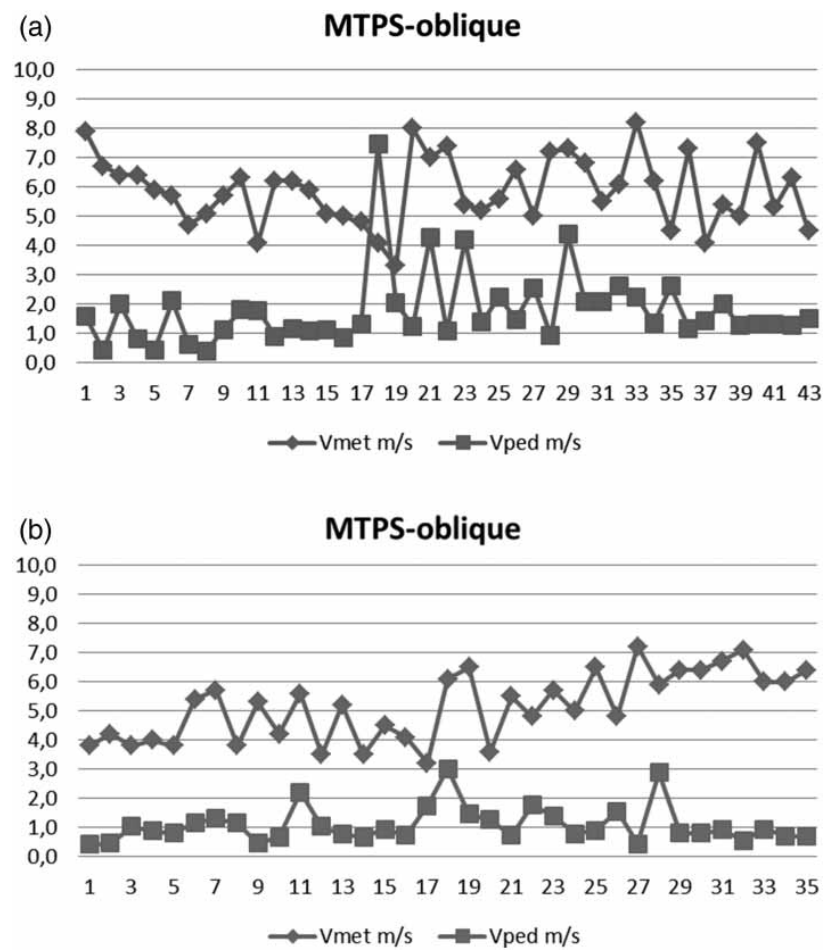

Figure 25. Measurements in MTPS in (a) August and (b) September, AFT period under oblique upwind direction: $V_{\text {met }}$ and $V_{\text {ped }}$ (y-axis), the measurement order of the points $(x$-axis). during daytime and $3.05 \mathrm{~m} / \mathrm{s}$ (in Fevzi Paşa BoulevardFVZPS) and $3.12 \mathrm{~m} / \mathrm{s}$ (in Gazi Boulevard-GZBL) during afternoon periods (Figure 15). In the daytime period (MID) the upwind is generally (in 59-61\% of the measurements) parallel to the canyon axis while it is oblique (in $84-87 \%$ of the measurements) in the afternoon periods. The mean standard deviation in Fevzi Paşa Boulevard is 0.14 and 0.10 in Gazi Boulevard which has a double tree row along the axis and more uniform building heights compared with the parallel canyon (Figure 16). In both the canyons the percentages of the number of measurements from cross-type points are higher than in the other canyons ( $42 \%$ in FVZPS and $48 \%$ in GZBL).

\section{The effect of the upwind direction and velocity on the pedestrian-level wind velocity along the canyons}

Analyses on the effect of the upwind velocity and direction on the pedestrian-level wind velocity have been made along the canyon axes. The upwind velocity $\left(V_{\text {met }}\right)$ and pedestrianlevel wind velocity $\left(V_{\text {ped }}\right)$ data along the streets are selected according to different upwind directions (parallel, oblique and normal) where all points are in the measurement order: In Konak, measurements start from the nearest location of the street to the seaside whereas in Alsancak they start from the North end of the street towards the South end and in Güzelyalı in the West-East direction (parallel to the seaside) (Figure 7(a)-(c)).

In the MID period when the upwind direction is normal to the canyon axes of Fevzi Paşa (FVZPS) and Gazi Boulevards (GZBL), apart from several measurements from the cross-type points, the pedestrian-level wind velocity varies between $1 \mathrm{~m} / \mathrm{s}$ and $2 \mathrm{~m} / \mathrm{s}$ although the upwind velocity $\left(V_{\text {met }}\right)$ is quite high (Figure 17(a) and 17(b)).

When the upwind direction is parallel to canyon axes, at both ends of the canyons and at some of the cross- and tshape-type points $V_{\text {ped }}$ has higher value than the average pedestrian-level wind velocity (Figures 18(a) and 18(b) and 19(a) and 19(b)): In August in FVZPS on the 2nd (CRSS), 7th (TSHP), 23rd (CRSS) and 26th (CRSS) points (Figure 18(a)) and in GZBL on the 2nd (CRSS), 6th (TSHP), 9th (SFTCRSS), 20th (TSHP) and 22nd (CRSS) points (Figure 18(b)), in September in FVZPS on the 2nd (CRSS) and 19th (CRSS) points (Figure 19(a)) and in GZBL on the 3rd (CRSS), 6th (TSHP) 19th (TSHP) and 21 st (TSHP) points (Figure 19(b)).

The pedestrian-level wind velocity $\left(V_{\text {ped }}\right)$ measurements show that at the middle part of the two parallel canyons under parallel upwind directions, the friction between the air and the surfaces along the streets results in lower $V_{\text {ped }}$ values. On the other hand, even with the parallel upwind direction the secondary streets intersecting with parallel canyons enhance the pedestrian-level wind velocity.

In the AFT period in July and August under oblique upwind direction in both measurements $V_{\text {ped }}$ varies and 
reaches higher levels at the East ends of the canyons where there are intersections of boulevards (Figures 20(a) and 20(b) and 21(a) and 21(b)).

In Alsancak in the MID period, during most of the measurements the upwind direction is oblique to canyon axes. With the help of the secondary streets channelling the air to the parallel canyons (Kibris Sehitleri (KBSS) and Ýkinci Kordon (2KRD) streets), at cross-type junctions $V_{\text {ped }}$ is higher than at the other measurement points: on the 11th (TSHP) 14th (SFTCRSS) and 17th (CRSS) points (Figure 22(a)).

Ýkinci Kordon (2KRD) is the first parallel street to the seaside. Therefore, at cross-type junctions $V_{\text {ped }}$ values reach the upwind velocity $\left(V_{\text {met }}\right)$ : on the 1 st (CRSS), 3rd (CRSS), 4th (TSHP), 7th (CRSS), 11th (CRSS) points in Figure 22(b).

In August under oblique upwind direction, crossand t-shape-type junctions play an important role in the acceleration of the pedestrian-level wind velocity: On the 10th (TSHP), 11th (TSHP) and 15th (CRSS) points in Figure 23(a) and on the 4th (CRSS), 6th (TSHP), 13th (CRSS), 16th (CRSS) and 18th (CRSS) points in Figure 23(b).

In the Güzelyalı site, during the MID and AFT periods in August and September the $V_{\text {ped }}$ measurements of the average pedestrian-level wind velocity are from cross, t-shaped points and also from the openings on the ground level of the buildings on the first row (Figures 24(a) and 24(b) and 25(a) and 25(b)). Apart from few points although the average upwind velocity is high (MID period in September and AFT period in August) the wind velocity at the pedestrian level remains low. In August on the 3rd and 11th points $V_{\text {ped }}$ is higher than $V_{\text {met }}$ with the help of the pedestrian-level openings (Figure 24(a)). In September the measurements where $V_{\text {ped }}$ is higher than the average pedestrian-level wind velocity are taken from TSHP (11th), SFTCRSS (18th) and PDST (28th) type points (Figure 24(b)).

The observations and measurements from the selected sites prove that the connection of the street canyons in sea-land direction is necessary for higher pedestrian-level wind velocity profile along the streets. In Alsancak, the aspect ratio $(H / W)$ of the canyons is lower than in Konak. However, the parallel upwind direction over the streets perpendicular to the seaside is not enough for obtaining higher pedestrian-level wind speed than in the actual measurements. Therefore, the intersection of the streets, the continuity of the secondary streets as air channels and controlling the length of the canyons are needed.

\section{Natural ventilation potential in the selected areas}

In Alsancak during the MID period, the number of crosstype junctions created by the intersections with the secondary canyons allowed the wind to reach the inner parts where it was needed. In the AFT period, the same connectivity is necessary for reverse wind flow from the land to the sea (Figure 26).

In the Konak site, in MID period, the average wind direction was from the West and the North (Figure 27). Gazi Boulevard (GZBL) and Fevzi Paşa Boulevard (FVZPS) are already open to the western wind by their perpendicular orientations to the shore line. However, for a better channelling of the northern wind in the MID period and of the NE wind in the AFT period, the secondary canyons or streets should be arranged in a more connected way with less obstruction.

The double tree row on the street axis in GZBL creates a more comfortable environment for pedestrians and also for people travelling in their vehicles compared with the situation in FVZPS (Figure 27). In the summer conditions, pedestrian comfort is expected to be higher due to the shadow provided by vegetation.

The average wind direction in the GZYL site in the MID period is in parallel and in normal directions to the axis of the MTPS canyon. However, due to continuous buildings with few openings on the first building row on the seaside, secondary canyons normal to MTPS have difficulties in channelling the air. The openings on the first row should be arranged so as to minimize the wind shadow effect in MTPS and in a corresponding way to the secondary canyon axes in order to channel the wind flow to the inner parts (Figure 28). In the AFT period, the same geometrical solutions are needed so as to channel the wind flow in the NE direction.

\section{Conclusions}

Air velocity at the pedestrian level is greatly affected by the presence of buildings. Even in streets with lower $H / W$ ratios, when $0<H / W \leq 1$, the canyon effect can be seen as lower pedestrian-level wind speeds. In addition, the uniformity of building heights has a negative effect on enhancing pedestrian-level wind speed. The angle of the upwind has an important effect, when it is perpendicular to the canyon axis, resulting in wind speeds lower than $3 \mathrm{~m} / \mathrm{s}$ at the pedestrian level. With an oblique upwind direction to the canyon axes, cross-type points play a role in enhancing the wind speed at the pedestrian level. When the wind flow is parallel to the canyon, the relation with the upwind and pedestrian wind has a relatively higher relationship. However, the friction along the canyon and therefore the deflection of the wind upwards, lowers wind speed.

During the afternoon periods the $V_{\text {met }} / V_{\text {ped }}$ ratio has lower values when compared with the midday period due to the thermal effect. After sunset, the surrounding air becomes cooler while the surfaces along the canyon become warmer due to the solar heat storage capacity of the materials. Consequently, the $V_{\text {ped }}$ increase is the result of this temperature difference.

Orientation of the streets in the N-S direction with higher aspect ratios $(1<H / W)$ provides shadow for pedestrians. However, in these locations appropriate natural ventilation required for the pedestrian comfort can be maintained by 
systematic cross-connections open to prevailing and local winds.

In further studies, the design of the ideal pattern of crossjunctions and the appropriate length of the canyons should be tested by simulation methods. When the wind flow is parallel to the canyon axes, based on the $V_{\text {met }} / V_{\text {ped }}$ diagrams $V_{\text {ped }}$ relatively drops compared with $V_{\text {met }}$ in the middle of the canyons. This is due to several reasons one of which is the friction forces on the canyon surfaces.

Based on this field study, future studies should consider natural ventilation potentials and alternative scenarios need to be tested by means of computer and wind tunnel simulations in order to find solutions for appropriate natural ventilation and comfort provided by winds.

\section{References}

Ahmad, K., M. Khare, and K. K. Chaundry. 2005. "Wind Tunnel Studies on Dispersion at Urban Street Canyons and Intersections - A Review." Journal of Wind Engineering and Industrial Aerodynamics 93 (9): 697-717.

Blocken, B., T. Stathopoulos, P. Saathoff, and X. Wang. 2008. "Numerical Evaluation of Pollutant Dispersion in the Built Environment: Comparisons Between Models and Experiments." Journal of Wind Engineering and Industrial Aerodynamics 96 (10-11): 1817-1831.

Buonanno, G., F. C. Fuoco, and L. Stabile. 2011. "Influential Parameters on Particle Exposure of Pedestrians in Urban Microenvironments." Atmospheric Environment 45 (3): 1434-1443.

Carpentieri, M., P. Salizzoni, A. Robins, and L. Soulhac. 2012. "Evaluation of a Neighbourhood Scale, Street Network Dispersion Model Through Comparison with Wind Tunnel Data." Environmental Modelling \& Software 37 (11): $110-124$.

Erell, E. 2008. "The Application of Urban Climate Research in the Design of Cities." In Advances in Building Energy Research, vol. 2, ed. M. Santamouris, 95-121. Trowbridge/London, UK: Cromwell/Earthscan.

Gallo, K. P., J. D. Tarpley, A. L. McNab, and T. R. Karl. 1995. "Assessment of Urban Heat Islands: A Satellite Perspective." Atmospheric Research 37 (7): 1-3.

Gao, Y., R. Yao, B. Li, E. Turkbeyler, Q. Luo, and A. Short. 2012. "Field Studies on the Effect of Built Forms on Urban Wind Environments." Renewable Energy 46 (10): 148-154.

Georgakis, C., and M. Santamouris. 2006. "Experimental Investigation of Air Flow and Temperature Distribution in Deep Urban Canyons." Energy and Buildings 38 (4): 367-376.

Georgakis, C., and M. Santamouris. 2008. "On the Estimation of Wind Speed in Urban Canyons for Ventilation Purposes - Part 1: Coupling Between the Undisturbed Wind Speed and the Canyon Wind." Building and Environment 43 (8): 1404-1410.

Givoni, B. 1998. Climate Considerations in Building and Urban Design. New York: Van Nostrand Reinhold.

Houghton, E. L., and N. B. Carruthers. 1976. Wind Forces on Buildings and Structures. New York: First published by Edward Arnold, published by Halsted Press, A Division of John Wiley.

Karatasou, S., M. Santamouris, and V. Geros. 2006. "Urban Building Climatology." In Environmental Design of Urban Buildings, an Integrated Approach, ed. M. Santamouris, 95-119. London: Earthscan.
Kenworthy, A. T. 1985. "Wind as an Influential Factor in the Orientation of the Orthogonal Street Grid." Building and Environment 20 (1): 33-38.

Kitous, S., R. Bensalem, and L. Adolphe. 2012. “Airflow Patterns Within a Complex Urban Topography under Hot and Dry Climate in the Algerian Sahara." Building and Environment 56 (10): 162-175.

Moonen, P., T. Defraeye, V. Dorer, B. Blocken, and J. Carmeliet. 2012. "Urban Physics: Effect of the Micro-climate on Comfort, Health and Energy Demand." Frontiers of Architectural Research 1 (9): 197-228.

$\mathrm{Ng}$, E., C. Yuan, L. Chen, and C. Ren. 2011. "Improving the Wind Environment in High-Density Cities by Understanding Urban Morphology and Surface Roughness: A Study in Hong Kong." Landscape and Urban Planning 101 (1): 59-74.

Niachou, K., I. Livada, and M. Santamouris. 2008a. "Experimental Study of Temperature and Airflow Distribution Inside an Urban Street Canyon During Hot Summer Weather Conditions - Part I: Air and Surface Temperatures.” Building and Environment 43 (8): 1383-1392.

Niachou, K., I. Livada, and M. Santamouris. 2008b. "Experimental Study of Temperature and Airflow Distribution Inside an Urban Street Canyon During Hot Summer Weather Conditions - Part II: Airflow Analysis." Building and Environment 43 (8): 1393-1403.

Oke, T. R. 1988. "Street Design and Urban Canopy Layer Climate." Energy and Buildings 11 (1-3): 103-113.

Pongrácz, R., J. Bartholy, and Z. Dezső. 2006. "Remotely Sensed Thermal Environment Applied to Urban Climate Analysis." Advances in Space Research 37 (12): 2191-2196.

Pongrácz, R., J. Bartholy, and Z. Dezső. 2010. "Application of Remotely Sensed Thermal Information to Urban Climatology of Central European Cities." Physics and Chemistry of the Earth, Parts $A / B / C 35$ (1-2): 95-99.

Santamouris, M. 1998. "Energy in the Built Environment: The Role of Natural Ventilation." In Natural Ventilation in Buildings: A Design Handbook, ed. F. Allard. London: James and James (Science Publishers).

Santamouris, M. 2001. "The Canyon Effect." In Energy and Climate in the Urban Built Environment, ed. M. Santamouris, 69-96. London: James \& James (Science Publishers).

Santamouris, M. 2007. "Heat Island Research in Europe: The State of the Art." In Advances in Building Energy Research 1, ed. M. Santamouris, 123-150. Trowbridge/London, UK: Cromwell/Earthscan.

Santamouris, M., C. Georgakis, and A. Niachou. 2008. "On the Estimation of Wind Speed in Urban Canyons for Ventilation Purposes. Part II: Using of Data Driven Techniques to Calculate the More Probable Wind Speed in Urban Canyons for Low Ambient Wind Speeds." Building and Environment 43 (8): 1411-1418.

Santamouris, M., N. Papanikolaou, I. Livada, I. Koronakis, C. Georgakis, A. Argiriou, and D. N. Assimakopoulos. 2001. "On the Impact of Urban Climate on the Energy Consumption of Buildings." Solar Energy 70 (3): 201-216.

Sobrino, J. A., R. Oltra-Carrio, G. Soria, R. Bianchi, and M. Paganini. 2012. "Impact of Spatial Resolution and Satellite Overpass Time on Evaluation of the Surface Urban Heat Island Effects." Remote Sensing of Environment 117 (2): $50-56$.

Tayanç, M., and H. Toros. 1997. "Urbanization Effects on Regional Climate Change in the Case of Four Large Cities of Turkey." Climatic Change 35 (4): 501-524.

Yamartino, R. J., and G. Wiegand. 1986. "Development and Evaluation of Simple Models for the Flow, Turbulence and Pollutant Concentration Fields Within an Urban Street Canyon." Atmospheric Environment 20 (11): 2137-2156. 